\title{
Real-time multivariate indices for the boreal summer intraseasonal oscillation over the Asian summer monsoon region
}

\author{
June-Yi Lee $\cdot$ Bin Wang $\cdot$ Matthew C. Wheeler $\cdot$ \\ Xiouhua Fu $\cdot$ Duane E. Waliser $\cdot$ In-Sik Kang
}

Received: 11 May 2012/Accepted: 25 September 2012/Published online: 21 October 2012

(C) The Author(s) 2012. This article is published with open access at Springerlink.com

\begin{abstract}
The boreal summer intraseasonal oscillation (BSISO) of the Asian summer monsoon (ASM) is one of the most prominent sources of short-term climate variability in the global monsoon system. Compared with the related Madden-Julian Oscillation (MJO) it is more complex in nature, with prominent northward propagation and variability extending much further from the equator. In order to facilitate detection, monitoring and prediction of the BSISO we suggest two real-time indices: BSISO1 and BSISO2, based on multivariate empirical orthogonal function (MV-EOF) analysis of daily anomalies of outgoing longwave radiation (OLR) and zonal wind at $850 \mathrm{hPa}(\mathrm{U} 850)$ in the region $10^{\circ} \mathrm{S}-40^{\circ} \mathrm{N}, 40^{\circ}-160^{\circ} \mathrm{E}$, for the extended boreal summer (May-October) season over the 30-year period 1981-2010. BSISO1 is defined by the first two principal components (PCs) of the MV-EOF analysis, which together
\end{abstract}

J.-Y. Lee $(\bowtie) \cdot$ B. Wang $\cdot$ X. Fu

International Pacific Research Center, University of Hawaii, POST Bldg, Room 409A, 1680 East-West Road,

Honolulu, HI 96822, USA

e-mail: juneyi@hawaii.edu

B. Wang $\cdot$ X. Fu

Department of Meteorology, University of Hawaii, Honolulu, HI, USA

M. C. Wheeler

Centre for Australia Weather and Climate Research (CAWCR),

Bureau of Meteorology, Melbourne, Australia

D. E. Waliser

JIFRESSE, University of California, Los Angeles, USA

D. E. Waliser

Jet Propulsion Laboratory, Caltech, Pasadena, USA

I.-S. Kang

Seoul National University, Seoul, Korea represent the canonical northward propagating variability that often occurs in conjunction with the eastward $\mathrm{MJO}$ with quasi-oscillating periods of 30-60 days. BSISO2 is defined by the third and fourth PCs, which together mainly capture the northward/northwestward propagating variability with periods of 10-30 days during primarily the pre-monsoon and monsoon-onset season. The BSISO1 circulation cells are more Rossby wave like with a northwest to southeast slope, whereas the circulation associated with $\mathrm{BSISO} 2$ is more elongated and front-like with a southwest to northeast slope. BSISO2 is shown to modulate the timing of the onset of Indian and South China Sea monsoons. Together, the two BSISO indices are capable of describing a large fraction of the total intraseasonal variability in the ASM region, and better represent the northward and northwestward propagation than the real-time multivariate MJO (RMM) index of Wheeler and Hendon.

Keywords Boreal summer intraseasonal oscillation . Madden-Julian Oscillation - Real-time multivariate index · Northward propagation - Asian summer monsoon .

Monsoon onset

\section{Introduction}

It has been well recognized that the tropical intraseasonal oscillation (ISO) exhibits prominent seasonal variation (Madden 1986, Wang and Rui 1990; Salby and Hendon 1994; Zhang and Dong 2004; CLIVAR Madden-Julian Oscillation (MJO) working group 2009; Kikuchi et al. 2012). Compared to boreal winter, during boreal summer the main centers of convective variability associated with the ISO are shifted away from the equator to $10-20^{\circ} \mathrm{N}$, and the propagation patterns are considerably more 
complicated. While the boreal winter ISO (also known as the MJO) shows predominantly eastward propagation, the boreal summer ISO (BSISO) also exhibits northward/ northeastward propagation over the Indian summer monsoon (ISM) region (Yasunari 1979, 1980; Krishnamurti and Subramanian 1982; Lau and Chan 1986; Wang et al. 2005; Annamalai and Sperber 2005), and northward/northwestward propagation over the Western North Pacific-East Asian (WNP-EA) region (Murakami 1984, Chen and Chen 1993; Kemball-Cook and Wang 2001; Kajikawa and Yasunari 2005; Yun et al. 2009, 2010), often in conjunction with MJO-like propagation along the equator (Lawrence and Webster 2002). Whereas the MJO has been regarded as applicable in all seasons, albeit with generally weaker variability in boreal summer (Madden and Julian 1972, 1994; Wheeler and Hendon 2004; Zhang 2005), the BSISO has been regarded as a specific mode of the tropical ISO that prevails in boreal summer (Wang and Xie 1997). Thus, for many applications it is instructive to consider the tropical ISO as described by two modes, the MJO and BSISO. The MJO dominates during boreal winter (December-April) and the BSISO dominates during boreal summer (June-October) with May and November being transitional months during which either mode may prevail (Kikuchi et al. 2012).

Importantly, the BSISO is the dominant source of shortterm climate variability in the Asian summer monsoon (Webster et al. 1998) and global monsoon (Wang and Ding 2008). It is known to affect summer monsoon onsets (Wang and Xie 1997; Kang et al. 1999), the active/break phases of the monsoon (Annamalai and Slingo 2001; Goswami 2005; Hoyos and Webster 2007; Ding and Wang 2009), and the monsoon seasonal mean (Krishnamurthy and Shukla 2007, 2008). It is also a possible source of seasonal climate predictability for precipitation (Wang et al. 2009a; Lee et al. 2010) and extratropical atmospheric circulation (Ding and Wang 2005; Lee et al. 2011; Wang et al. 2012). Two different periodicities of the BSISO have been identified: periods of 30-60 days (e.g., Wang et al. 2005) and 10-20 days (e.g., Kikuchi and Wang 2010). The wet and dry spells of the BSISO strongly influence extreme hydro-meteorological events, major driving forces of natural disasters, and thus the socio-economic activities in the World's most populous monsoon region (Lau and Waliser 2005).

Given the extreme importance of the BSISO, having real-time indices of it can assist immensely in monitoring and forecasting applications. For the MJO, the Real-time Multivariate MJO (RMM) index developed by Wheeler and Hendon (2004) is the most widely used for such applications (e.g. Leroy and Wheeler 2008; Wheeler et al. 2009; Gottschalck et al. 2010; Rashid et al. 2011). It is defined by the first two principal component time series of the multivariate empirical orthogonal function (MV-EOF) modes of the equatorial mean (between $15^{\circ} \mathrm{S}$ and $15^{\circ} \mathrm{N}$ ) outgoing longwave radiation (OLR; a good proxy for convection), and zonal winds at 850 (U850) and $200 \mathrm{hPa}$ (U200). The equatorial symmetric nature of the RMM index makes it an excellent measure of the equatorial eastward propagating mode, the MJO. However, since the RMM index is designed to depict all year round MJO activity, it is not expected to fully represent the seasonality of the ISO, especially during the peak of the boreal summer when ISO activity is furthest from the equator. Figure 1 shows the variance of pentad mean OLR after removing the climatological slow annual cycle (LinHo and Wang 2002) and interannual variability, separately for boreal winter (November to April) and summer (May to October), together with the fractional variance of the anomaly explained by the two-component RMM index during the two seasons. It is noted that the RMM index is capable of capturing a large fraction of the intraseasonal OLR variance during boreal winter over the major convective regions except over the South Pacific convergence zone. During boreal summer, on the other hand, the variance that is captured by the RMM is primarily confined between $5^{\circ} \mathrm{S}$ and $18^{\circ} \mathrm{N}$, and does not reach as far north into the Asian summer monsoon (ASM) region as has been documented for the BSISO. Improving upon the RMM index for real-time monitoring and prediction of the BSISO is the goal of the work presented in this paper.

There have been several attempts to define indices for the BSISO mainly using Eigen techniques (Lau and Chan 1986; Waliser et al. 2004; Annamalai and Sperber 2005; Kikuchi et al. 2012 and others). Most recently, Kikuchi et al. (2012) reviewed existing approaches and proposed a bimodal ISO index that includes a BSISO mode with prominent northward propagation and large variability in off-equatorial monsoon trough regions, and a MJO mode with predominant eastward propagation along the equatorial zone. Their index successfully identifies the summer and winter component of the tropical ISO, but still has some limitations to capture the BSISO particularly over the Bay of Bengal and WNP-EA region (Fig. 6 in Kikuchi et al. 2012). In addition, as the Kikuchi et al. (2012) index was defined using 25- to 90-day filtered data, complications arise when trying to apply it in real time and to the output of global numerical forecast models. Ideally we would like an index or indices of the BSISO that involve no time filtering, and thus no smearing of information across different observation days or different forecast lead times.

Section 2 describes the method to define the BSISO indices proposed in this study. Basic characteristics of the BSISO captured by the indices are presented in Sect. 3 . Section 4 describes the composite life cycle of the BSISO modes and fractional variance of OLR and U850 anomalies captured by the indices. How to apply the indices for realtime monitoring is discussed in Sect. 5. Summary and discussion are given in Sect. 6. 
(a) Variance of 5-day mean OLR anomaly after removing IAV

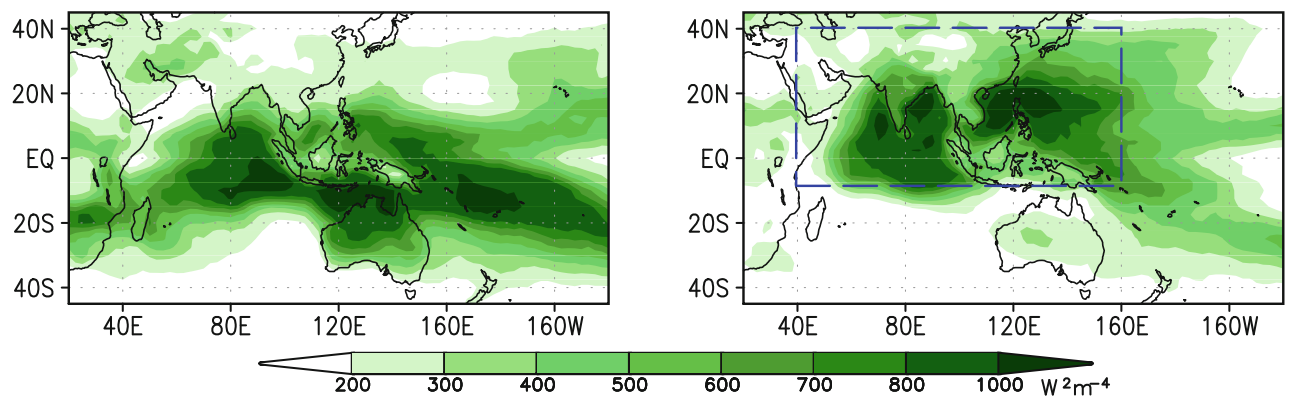

(b) Fractional variance explained by the two-component RMM index
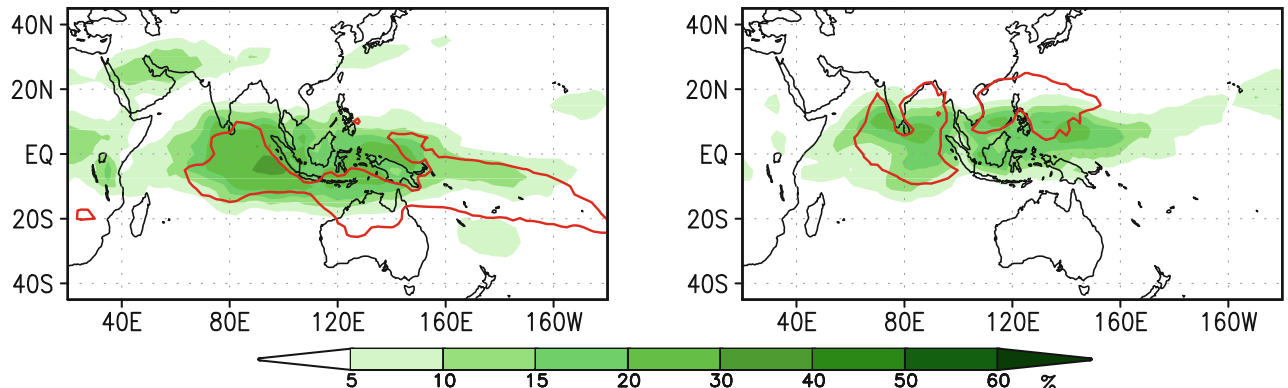

Fig. 1 a Variance of pentad mean OLR anomaly $\left(\mathrm{W}^{2} \mathrm{~m}^{-4}\right)$ after removing climatological annual cycle and interannual variability during November to April (NDJFMA) and May to October (MJJASO), respectively. b Fractional variance (\%) of 5-day mean

\section{Definition of BSISO indices}

\subsection{Data}

The data used include the daily Advanced Very High Resolution Radiometer (AVHRR) OLR with $2.5^{\circ}$ horizontal resolution from the National Oceanic and Atmospheric Administration (NOAA) polar orbiting satellites (Liebmann and Smith 1996) and daily horizontal wind at 850 and $200 \mathrm{hPa}$ from NCEP/Department of Energy (DOE) Reanalysis II (Kanamitsu et al. 2002) with $2.5^{\circ}$ horizontal resolution.

\subsection{Process to define BSISO indices}

The BSISO indices proposed in this study were designed to better represent fractional variance and the observed northward propagating ISO over the entire ASM region than the RMM index. After considerable sensitivity tests, our chosen method to define the new BSISO indices uses MV-EOF analysis of daily mean OLR and 850-hPa zonal wind (U850) anomalies over the ASM region $\left(10^{\circ} \mathrm{S}-40^{\circ} \mathrm{N}, 40^{\circ}-160^{\circ} \mathrm{E}\right)$ from 1st May to 31st October for the 30 years 1981-2010. The OLR and U850 anomalies were obtained by removing the slow annual cycle (mean and first three harmonics of climatological annual variation) as well as the effect of
OLR anomaly accounted by the two-component RMM index. Blue dashed line in right-hand side of a indicates the Asian summer monsoon (ASM) domain. Red contour in $\mathbf{b}$ represents OLR variability center with variance larger than $800 \mathrm{~W}^{2} \mathrm{~m}^{-4}$ shown in a

interannual variability by subtracting the running mean of the last 120 days as in Wheeler and Hendon (2004). We do not apply any other time filtering. After that, the two anomaly fields were each normalized by their area averaged temporal standard deviation over the ASM region. The normalization factor used is $33.04 \mathrm{~W} \mathrm{~m}^{-2}$ for OLR and $4.01 \mathrm{~m} \mathrm{~s}^{-1}$ for U850. After applying the MV-EOF on the normalized OLR and U850 anomalies, we identified the first four MV-EOF modes as important for representing the BSISO over the ASM region. The percentage variance accounted for by each mode is 7.2, 4.9, 3.8, and 3.5\% respectively (Figs. 2, 3). Thus, the first four modes can account for $19.4 \%$ of total daily variance of the combined OLR and U850 anomalies over the ASM region. Although the percentage variance for each mode is small, they are statistically distinguishable from each other and from higher modes according to the rule of North et al. (1982) (not shown) with an effective number of degrees of freedom of 1,520 among the total sample size of 5,520 estimated following Livezey and Chen (1983). It is the principal component time series, or projection coefficients (PCs), of the leading four modes that are used to define the BSISO indices.

Our reasons for using an MV-EOF of OLR and U850 in this analysis are based on both theoretical and practical considerations. From a theoretical point of view, we include both U850 and OLR since interaction between 
low-level atmospheric circulation and the major monsoon convective heat sources has been suggested as the main mechanism for the northward propagation of the BSISO (Wang and Xie 1997; Kemball-Cook and Wang 2001; Hsu and Weng 2001; Jiang et al. 2004; Annamalai and Sperber $2005)$. From a practical point of view, sensitivity tests indicate that a combination of OLR and U850 performs better than other variable combinations for defining the BSISO. Table 1 summarizes results from these sensitivity tests, focusing on the explained variance and spectral properties of the PCs of the leading two EOF modes from a variety of EOF analyses. The MV-EOF with OLR and U850 has the largest explained variance of the combinations tested $(12.1 \%$ compared to $9.3,9.6$, and $10.4 \%$ ). The fraction of the leading two PCs variance in the 30- to 60-day band is also near the largest for the OLR and U850 combination $(0.50$ compared to $0.52,0.46$, and 0.49 ). The coherence of the PCs derived from the chosen combination of OLR and U850 is also acceptably high in the 30- to 60-day band (0.48), indicating that the analysis likely captures a propagating intraseasonal phenomenon. Further analysis and details on the four MV-EOF modes and the derived BSISO indices will be provided in the following sections.

\section{Basic Characteristics of the BSISO Indices}

Based on our analysis, two BSISO indices are proposed in this study: BSISO1 comprising the 1 st and 2 nd MV-EOF modes, and BSISO 2 comprising the 3 rd and 4 th modes. As will be shown, BSISO1 represents the canonical northward propagating BSISO over the ASM region addressed in many previous studies with a 30-60 day quasi-oscillating period (e.g., Annamalai and Sperber 2005; Wang et al. 2005; Kikuchi et al. 2012). BSISO2, on the other hand, mainly captures the northward and northwestward propagating BSISO with periods of both around 30 days and 10-20 days (e.g., Kikuchi and Wang 2010).

\subsection{BSISO1: the canonical northward propagating BSISO component}

Figure 2 shows the spatial structures and PCs of the first two MV-EOF modes. To display the full horizontal wind vector, the associated meridional wind field at $850 \mathrm{hPa}$ (V850) was obtained by regressing V850 anomalies, normalized by their area-averaged temporal standard deviation (2.651 $\left.\mathrm{m} \mathrm{s}^{-1}\right)$, against each PC. The spatial structure of the

The Canonical Northward Propagating BSISO Component

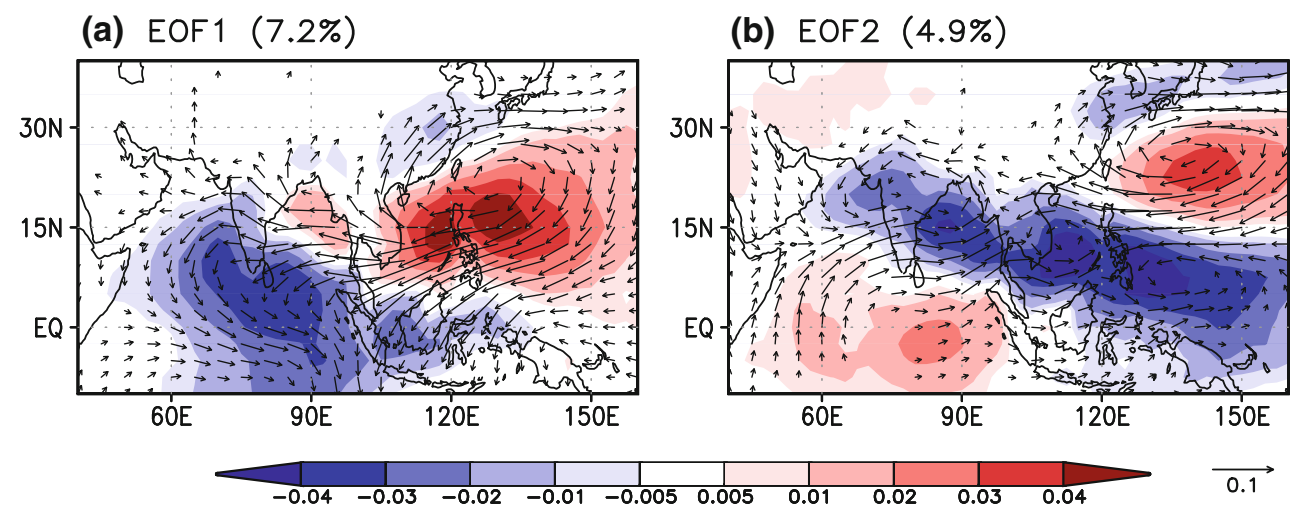

(c) $\mathrm{PC}$

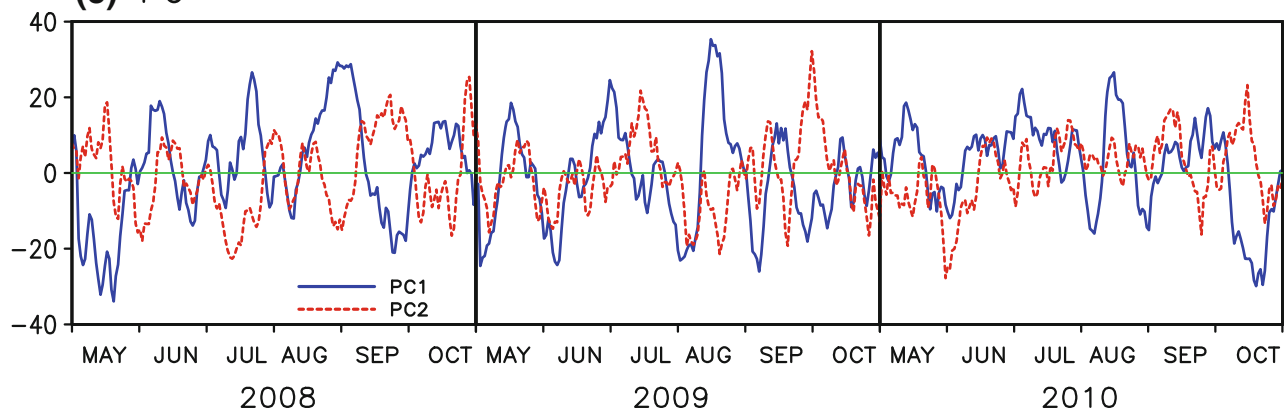

Fig. 2 Spatial structure (a, b) and PC time series (c) of the first two leading MV-EOF modes of daily OLR (shading) and zonal wind at $850 \mathrm{hPa}$ (U850) anomalies normalized by their area averaged temporal standard deviation over the ASM region $\left(33.04 \mathrm{~W} \mathrm{~m}^{-2}\right.$ for OLR and $4.01 \mathrm{~m} \mathrm{~s}^{-1}$ for U850). To display the full horizontal wind vector, the associated meridional wind at $850 \mathrm{hPa}$ (V850) was obtained by regressing V850 anomaly, normalize by its area averaged standard deviation (3.14 $\mathrm{m} \mathrm{s}^{-1}$ ), against each PC. The MV-EOF modes were obtained during MJJASO for the 30 years of 1981-2010 
The ASM Pre-monsoon and Onset Component

(a) EOF3 (3.8\%)

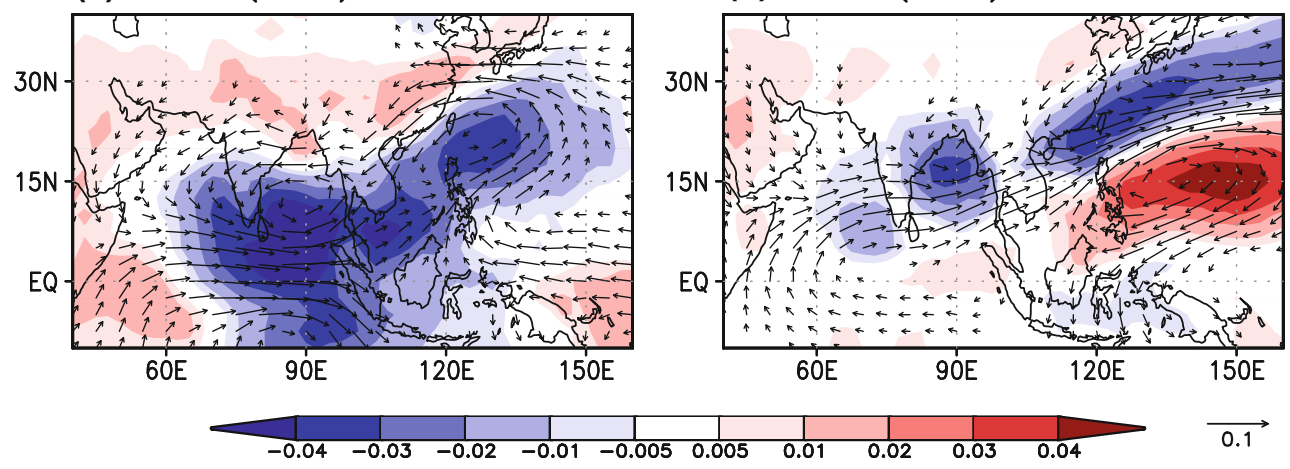

(c) $\mathrm{PC}$

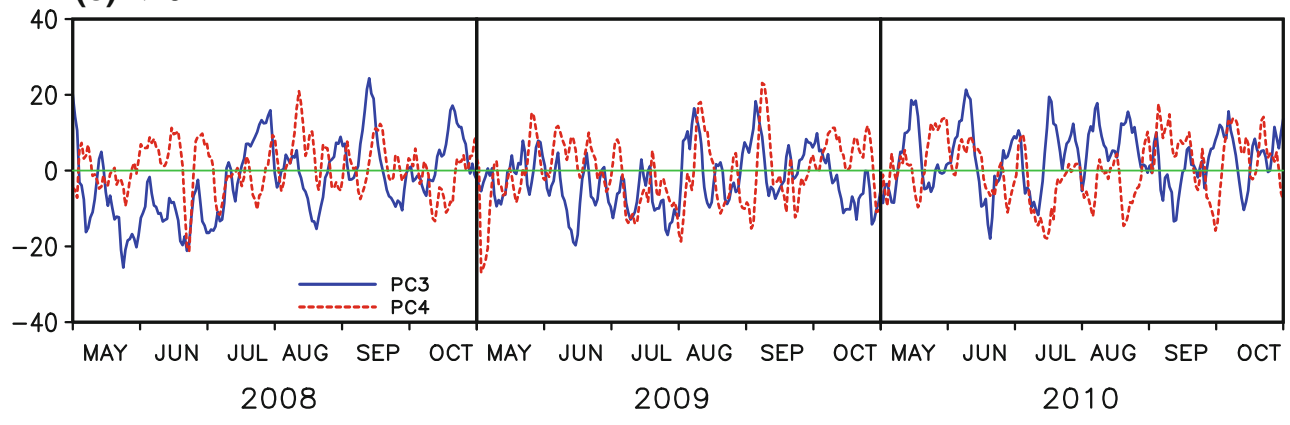

Fig. 3 Same as Fig. 2 except for the 3rd and 4th modes

Table 1 Summary of results from different EOF analyses

\begin{tabular}{llll}
\hline $\begin{array}{l}\text { Analyzed } \\
\text { field }\end{array}$ & $\begin{array}{l}\text { Explained } \\
\text { variance of } \\
\text { EOF1 and } \\
\text { EOF2 (\%) }\end{array}$ & $\begin{array}{l}\text { Fraction of } \\
\text { leading } \\
\text { PCs variance in } \\
\text { 30- to 60-day } \\
\text { band }\end{array}$ & $\begin{array}{l}\text { Mean } \mathrm{Coh}^{2} \text { of } \\
\text { 301 and PC2 in } \\
\text { band }\end{array}$ \\
\hline OLR' $^{\prime}$ and U850' & 12.1 & 0.50 & 0.48 \\
OLR' $^{\prime}$ & 9.3 & 0.52 & 0.59 \\
$\begin{array}{l}\text { OLR', U850', and } \\
\text { V850' }\end{array}$ & 9.6 & 0.46 & 0.44 \\
$\begin{array}{l}\text { OLR', U850', and } \\
\text { U200' }\end{array}$ & 10.4 & 0.49 & 0.43 \\
\hline
\end{tabular}

Climatological annual cycle and interannual variability were removed in the all analyzed field and then anomalies were normalized by the area-averaged standard deviation over the ASM region

first mode (EOF1) displays mostly an east-west seesaw pattern in OLR, while EOF2 shows more of a quadrupole pattern characterized by a north to south dipole over the ISM region, and an oppositely-directed (south to north) dipole over the WNP-EA region. The U850 component of the EOF spatial structures is in approximate quadrature with the OLR component, with westerly anomalies occurring to the north and east of the positive OLR anomalies, and vice versa for the easterlies. Similar between EOF1 and EOF2 is the characteristic northwest to southeast slope of their patterns. As will be discussed further, this similarity is the first suggestion that EOF1 and EOF2 should be treated together as a pair to form what we call BSISO1.

A sample of the PCs associated with the leading two EOFs is provided in Fig. 2c. Consistent with the ordering of EOF modes, the variations of PC1 can be seen to be slightly larger than those of PC2. During the years shown it can be seen that $\mathrm{PC} 1$ and $\mathrm{PC} 2$ mostly vary on the intraseasonal timescale, with $\mathrm{PC} 1$ often leading $\mathrm{PC} 2$ by about a quarter cycle. This provides further evidence supporting our inclusion of the first two EOF modes as a pair in BSISO1.

The mean seasonal cycle of variance of each of the PCs is shown in Fig. 4. For the months of the year outside of May to October (which was the season used for the EOF analysis), the "PC" data were obtained by projecting OLR and U850 anomalies onto the same EOF structures. Thus, in the months of November to March we use the "projection coefficients", and during the months of May to October the projection coefficients and principal components are equivalent (both of which we label as "PCs"). As required from the ordering of modes from the EOF analysis, PC1 has the greatest overall variance when averaged across boreal summer, followed 
Fig. 4 The mean seasonal cycle of variance of each of the four PCs for the 30 years of 1981-2010. 30-day running mean was applied

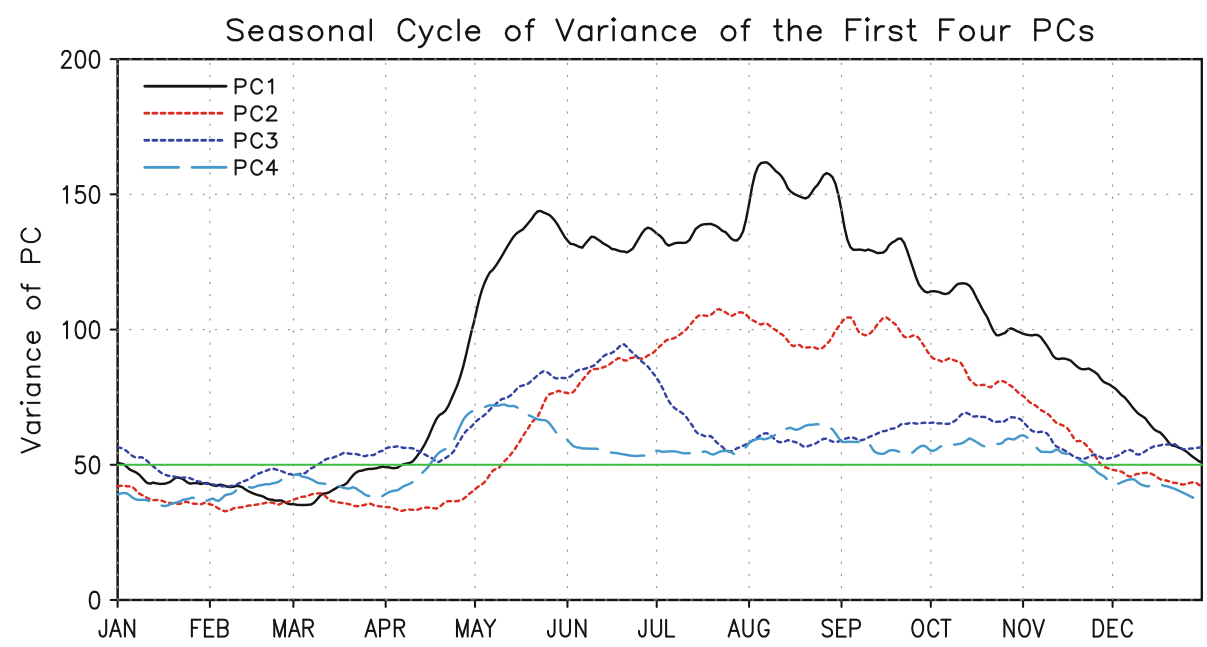

(a) PC1

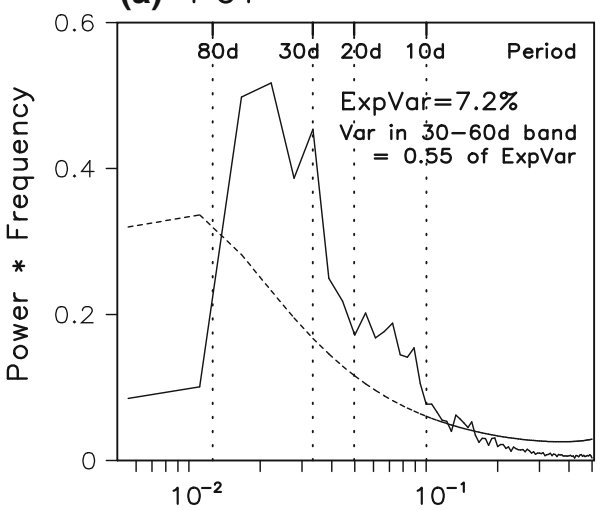

(b) $\mathrm{PC} 2$

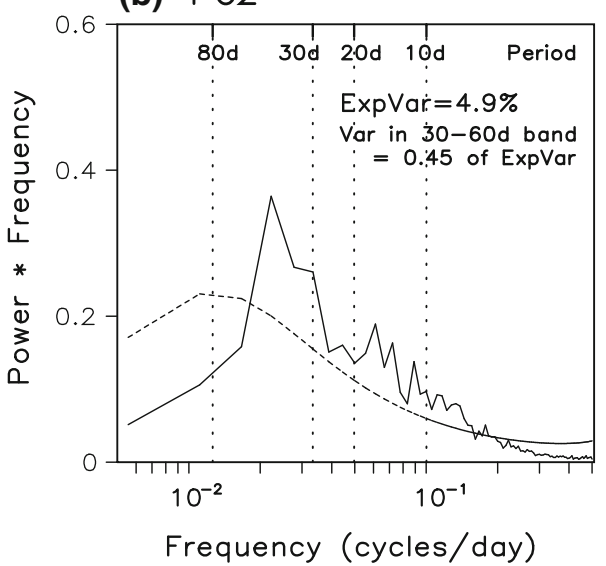

(c) $\mathrm{PC} 3$

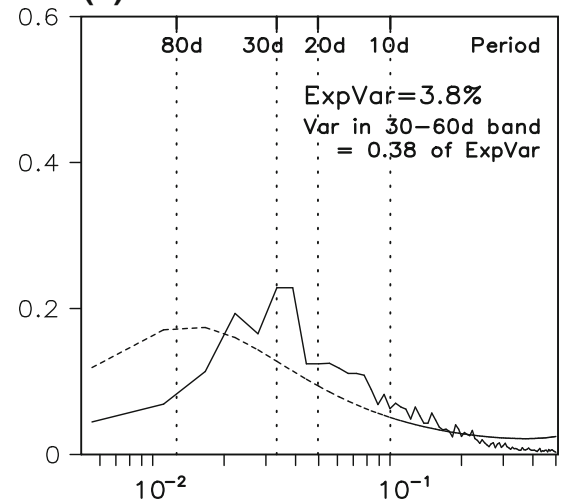

(d) PC4

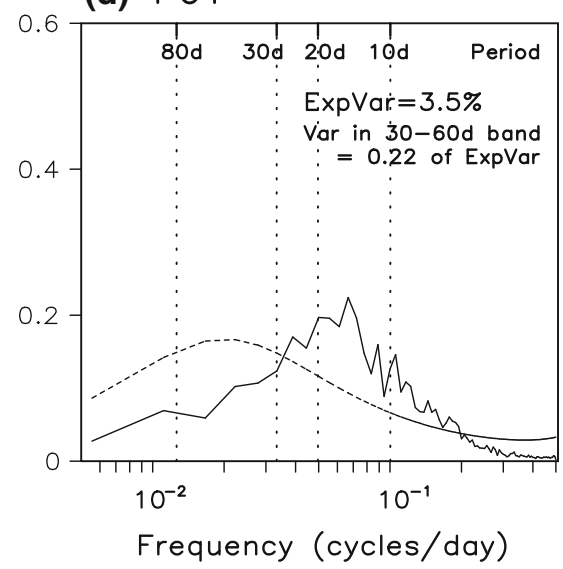

by $\mathrm{PC} 2$, and both have a similar seasonal cycle, with strong variance throughout the May to October period. Obviously, PC1 and $\mathrm{PC} 2$ (i.e. BSISO1) represent the dominant BSISO mode, and the similarity of their seasonal cycle is further evidence that they should be treated together. Interestingly, PC1 has an abrupt increase of variance around late April and early May with a double maximum of variance in May and August, while the seasonal cycle of $\mathrm{PC} 2$ variance tends to be delayed by about half a month.

Power spectra of the PCs are presented in Fig. 5. For PC1 and PC2, the bulk of the variance can be seen to be concentrated on intraseasonal periods of 30-60 days. The cross-spectra in Fig. 6 further show that PC1 and PC2 have greatest coherence in the 30- to 60-day range with a $90^{\circ}$ phase difference indicating that PC1 leads PC2 by a quarter 


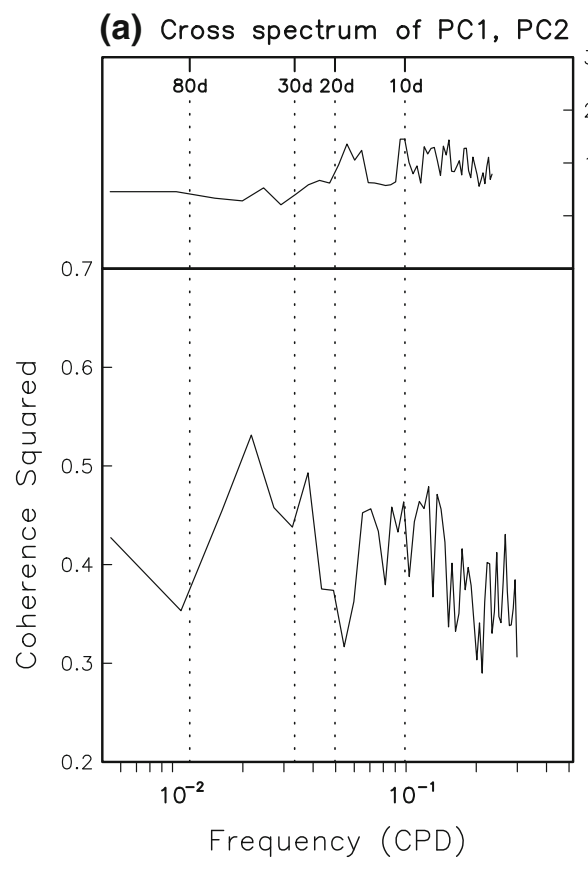

Fig. 6 a Coherence squared and phase between PC1 and PC2 of the EOF analysis of Fig. 2. The $0.1 \%$ confidence level on the null hypothesis of no association is 0.23 . For the phase, a $90^{\circ}$ relationship

(a) $\mathrm{PC} 1, \mathrm{PC} 2$

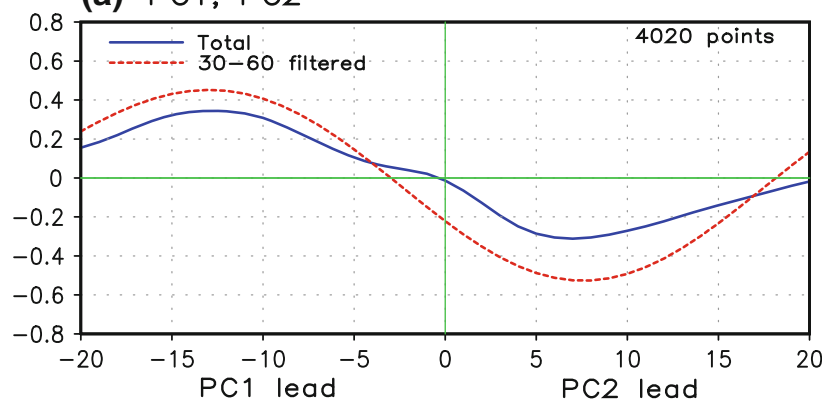

(b) $\mathrm{PC} 3, \mathrm{PC} 4$

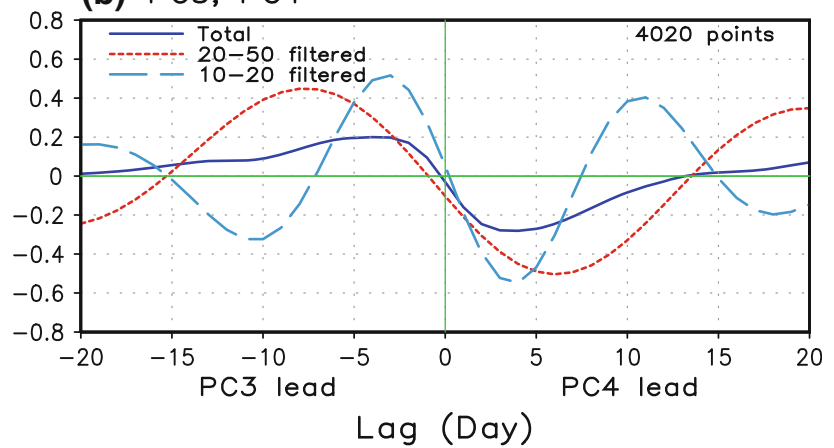

Fig. 7 Lead-lag correlation coefficients a between PC1 and PC2 and b between PC3 and PC4 during MJJASO for the 30 years of 1981-2010

cycle. This relatively strong coherence between PC1 and PC2 provides further justification for combining them in our BSISO1 index. (b) Cross spectrum of PC3, PC4

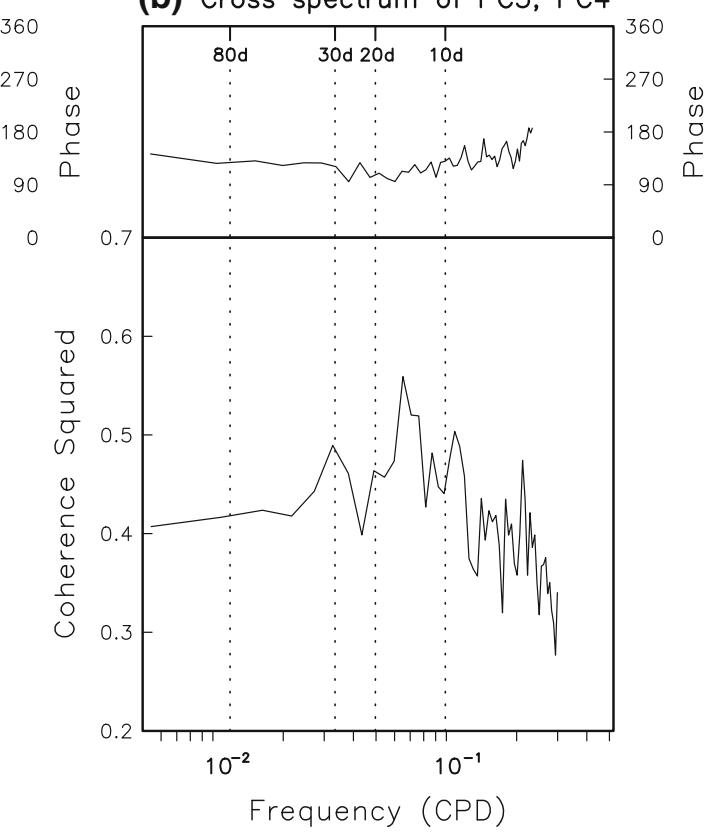

means that PC1 leads PC2 by a quarter cycle. $\mathbf{b}$ As in $\mathbf{a}$, except for the cross-spectrum between PC 3 and PC4. PC 3 leads PC4 by a quarter cycle

Lag correlations between the PCs are presented in Fig. 7. PC1 tends to lead PC2 by about 13 days with a maximum correlation of 0.34 for non-filtered data, and 0.45 for 30- to 60-day filtered data. It is further noted that PC1 and PC2 are significantly correlated with both RMM1 and RMM2 (from Wheeler and Hendon 2004). PC1 (PC2) is more significantly correlated with RMM2 (RMM1), having a maximum correlation of $-0.63(-0.48)$ at zero lag. This indicates that the canonical northward propagating ISO mode tends to occur in conjunction with the eastward propagating equatorial $\mathrm{MJO}$.

\subsection{BSISO2: The ASM pre-monsoon and onset component}

In this study we also consider the third and fourth MV-EOF modes and argue that they capture the northward and northwestward propagating component of the BSISO, particularly during the pre-monsoon and monsoon onset period (Wang and Xie 1997; LinHo and Wang 2002). Different to the first two modes, the OLR and U850 patterns in EOF3 and EOF4 tend to be more in phase over the ISM and WNP region with a southwest-northeast tilted horizontal structure (Fig. 3). That is, the westerlies are shifted to correspond more closely with the regions of negative OLR and the easterlies with positive OLR. The structure of EOF4 resembles the 'climatological ISO' of Kang et al. (1999; their Fig. 4e) and the fast annual cycle pattern of the pre-monsoon and onset period of Linho and 
Wang (2002; their Fig. 4a). Consistent with this resemblance, Fig. 4 shows that PC3 and PC4 have maximum variance from late May to early July, corresponding to the pre-monsoon and onset period. We are thus confident that the third and fourth MV-EOF modes identified in this study are linked with a previously-described physical mode of the climate system.

(a) BSISO1

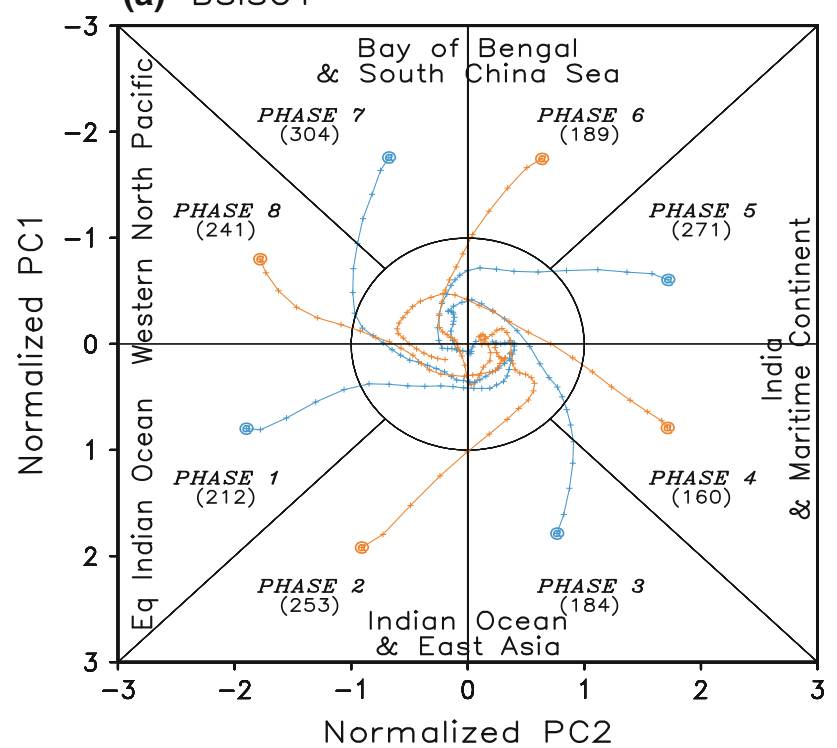

(b) $\mathrm{BSISO} 2$

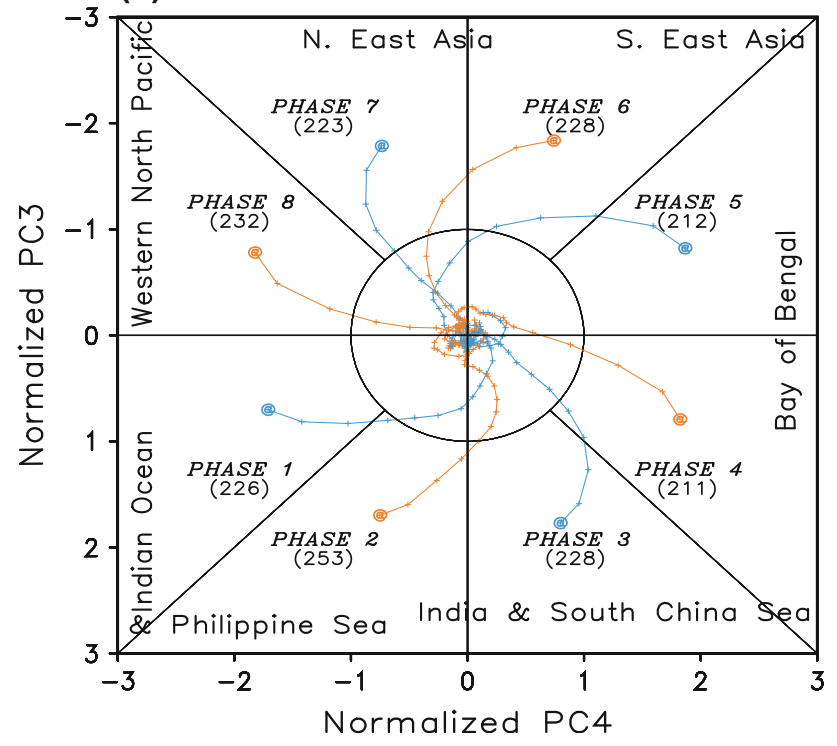

Fig. 8 a PC2 and PC1 phase space composite curves of BSISO1 [odd number (mid blue) and even number (orange) initial phase]. The PCs have each been normalized by their respective standard deviation. For each initial phases, storing cases are selected when the BSISO amplitude $\left(\mathrm{PC} 1^{2}+\mathrm{PC}^{2}\right)^{1 / 2}$ exceeded 1.5. Then, data for each of the next 30 days from the initial day are averaged over all strong cases to show the evolution of the BSISO index. b Same as a except for (PC4, PC3) phase space composite curves of BSISO2. The number of strong events used for each phase is given
The time variation of PC3 and PC4 is indicated for some sample years in Fig. 3c, indicating that these modes generally have a shorter time scale than $\mathrm{PC} 1$ and $\mathrm{PC} 2$ (Fig. 2c). Power spectra of PC3 and PC4 (Fig. 5c, d) confirm that the bulk of their variance is concentrated at around 30 days (PC3) and in the 10- to 20-day range (PC4). Further, PC3 and PC4 have high coherence in the 10 - to 20-day range and at $\sim 30$ days, with approximately $90^{\circ}$ phase difference (Fig. 6b). Analysis of the lag correlations between the two PCs shows that PC 3 tends to lead PC4 by about 3-4 days for variability in the 10- to 20-day period range, and at a lag of 7-8 days for variability in the 20- to 50-day range (Fig. 7b). These relatively high coherence values, their similar horizontal tilts, and similar climatological seasonal cycles lead us to conclude that the third and fourth MV-EOF modes should be treated together as a pair, which we call BSISO2.

Interestingly, BSISO2 is not well correlated with the eastward-propagating MJO as measured by RMM1 and RMM2. While PC4 has no significant correlation with either RMM1 or RMM2, PC3 is correlated with RMM1 having a maximum correlation of 0.47 when PC 3 leads RMM1 by about 3 days, but not significantly correlated with RMM2. Thus the linkage between BSISO2 and the eastward MJO is very weak.

\section{Composite Life Cycles and Fractional Variance}

Further understanding of the structure and patterns of variability captured by BSISO1 (EOFs 1 and 2) and BSISO2 (EOFs 3 and 4) can be achieved by constructing composites in a similar fashion to what was done for the MJO by Wheeler and Hendon (2004). Given the strong lead-lag behavior of PC1 and PC2, it is convenient to diagnose the state of BSISO1 as a point in the twodimensional phase space defined by PC1 and PC2. Using the same argument, we diagnose $\mathrm{BSISO} 2$ as a point in the two-dimensional phase space defined by PC 3 and PC4. In this analysis we use the normalized versions of the PCs, calculated by dividing by their 1981-2010 May-October standard deviations, to construct each phase space.

\subsection{BSISO1 composite life cycle}

Figure $8 \mathrm{a}$ shows the $\mathrm{PC} 1$ and $\mathrm{PC} 2$ phase space composite curves of the BSISO1 index for events that initially have an amplitude greater than 1.5 (i.e. $\left(\mathrm{PC}^{2}+\mathrm{PC}^{2}\right)^{1 / 2}>1.5$ ). Like Wheeler and Hendon (2004), we divide the phase space into eight phases, and for each phase we composite 30-day segments using the same approach as Kim et al. (2009). Strong BSISO1 events can be seen to persist in their evolution up to 10-20 days. When considering all 
Fig. 9 The life cycle composite of OLR (shading) and 850-hPa wind (vector) anomaly reconstructed based on $\mathrm{PC} 1$ and PC2 of BSISO1 in 8 phases. Composite maps shown are masked to exhibit only anomalies that exceed a twotailed Normal-z test at the $95 \%$ confidence level
BSISO 1

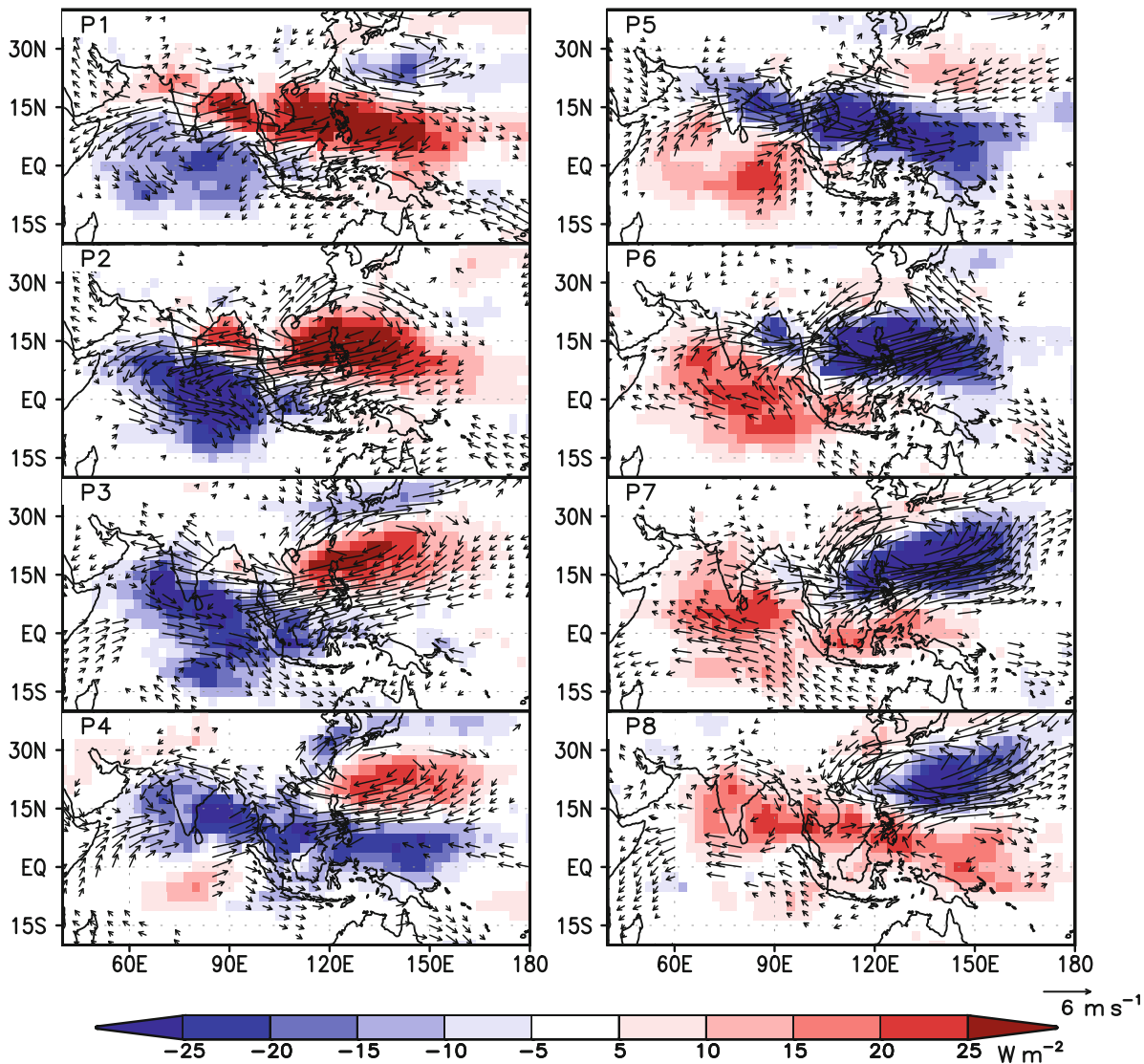

events in a non-composite sense, the average time between successive phases is 5.5 days, a little less than the 6 days quoted for the MJO by Wheeler and Hendon (2004).

We also make composites of the convection and circulation fields for each of the eight phases, as displayed in Fig. 9, using the same amplitude threshold of 1.5. Composite maps shown are masked to exhibit only anomalies that exceed a two-tailed Normal-z test at the $95 \%$ confidence level. It can be seen that convection associated with BSISO1 first appears over the equatorial Indian Ocean in Phase 1 , and then propagates northeastward reaching the Indian Subcontinent in Phase 3 and the Bay of Bengal in Phases 4-5. The convection over the equatorial Indian Ocean also propagates eastward from Phase 1 and reaches the Maritime continent in Phases 3-4. Then, the convection propagates northward reaching the South China Sea in Phase 7, the WNP in Phase 8, and East Asia with weakened amplitude in Phase 3-4. Figure 9 demonstrates that BSISO1 is able to better represent the northward/northeastward propagating pattern over the ASM region than the RMM (compare with Fig. 9 of Wheeler and Hendon 2004).

It is interesting to note from Fig. 8a that Phase 5 (271 cases) and 7 (304 cases) are the most favorable for the strong initial events while Phase 3 (184 cases), 4 (160 cases), and 6 (189 cases) are the least favorable. This may indicate that the northwest-southeast tilted rainband from the Indian subcontinent to the equatorial Western Pacific tends to strengthen from Phase 3-5 then weaken. The amplitude then increases in Phase 7, associated with the cyclonic Rossby gyre over the WNP-EA region, which then propagates northwestward with weakened amplitude. It may also be associated with a slowdown of ISO propagation in Phases 5 and 7. The phase preference for the strong initial events needs further investigation.

\subsection{BSISO2 composite life cycle}

Figure $8 \mathrm{~b}$ depicts the PC3 and PC4 phase space composite curves of the BSISO2 index. The life cycle of BSISO2 is shorter than BSISO1, with all curves reaching the centre of the phase space within 30 days. The average interval time between phases is 3.2 days. In general, the BSISO1 and BSISO2 tend to decay quicker than the MJO (see Fig. 7 of Wheeler and Hendon 2004), implying that the BSISO may have lower predictability than the MJO.

Figure 10 shows the composite convection and circulation fields of BSISO 2 based on the eight phases as defined in Fig. 8b. The convection is located in the equatorial 
Fig. 10 Same as Fig. 9 except for $\mathrm{PC} 3$ and $\mathrm{PC} 4$ of $\mathrm{BSISO} 2$
$\mathrm{BSISO} 2$

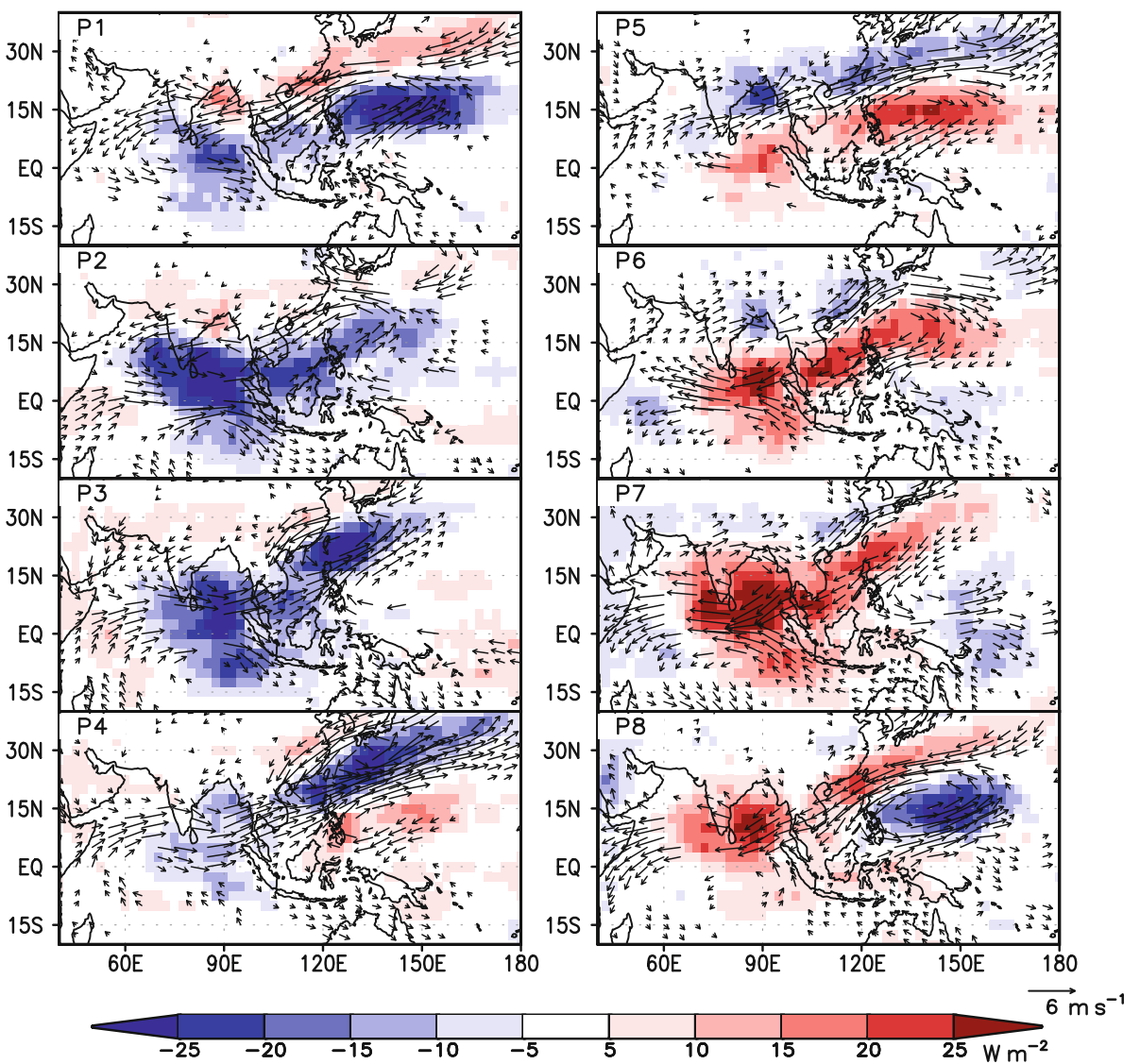

(a) Indian Monsoon Onset

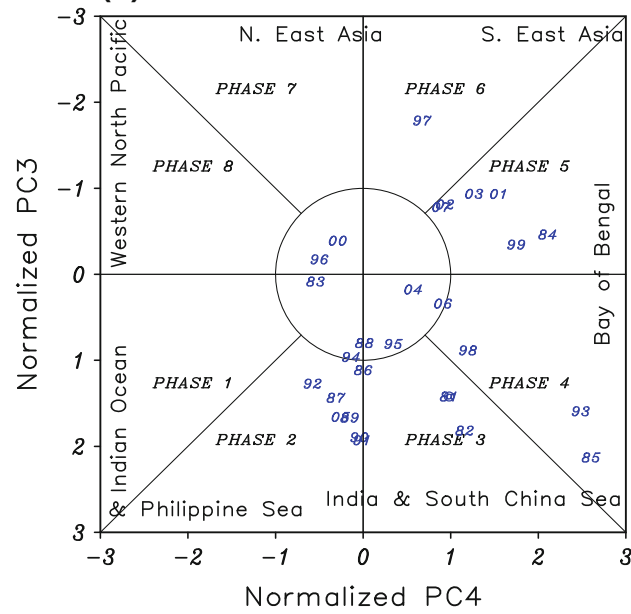

Fig. 11 a PC4 and PC3 phase points (as marked by the small dual numbers) for monsoon onset dates at Kerala, India from India Meteorological Department (IMD) from 1981 to 2007. b Same as

Indian Ocean and Philippine Sea in Phase 1 and then propagates northwestward over the Indian longitude as well as the WNP-EA region. While the atmospheric circulation associated with BSISO1 exhibits a Rossby-type response, the circulation of BSISO2 is more elongated and front-like, (b) SCS Monsoon Onset

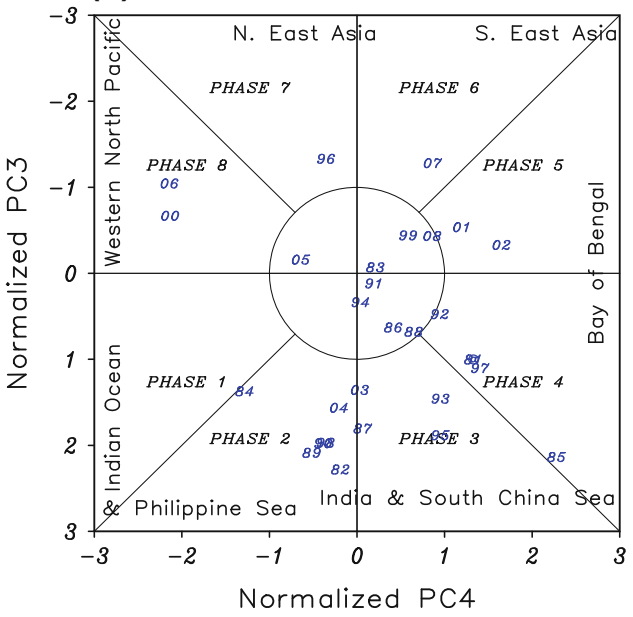

a except for South China Sea monsoon onset dates defined by Kajikawa and Wang (2012) from 1981 to 2008

particularly over the WNP-EA region. As already mentioned, this structure resembles the first fast annual cycle pattern from of LinHo and Wang (2002). Thus, BSISO2 somewhat represents stepwise monsoon onset over the ASM region, particularly over the Bay of Bengal and 
Fig. 12 Spatial distribution of fractional variance of pentad a OLR and b U850 anomaly that are accounted for by the first two PCs (BSISO1 only in upper panels), the first four PCs (BSISO1 and BSISO2 in middle panels) and the two-component RMM index (lower panels). Red solid (dashed) line indicates fractional variance at $50 \%$ $(20 \%)$

Fig. 13 Time series of a PC1 and $\mathrm{PC} 2$ and $\mathbf{b} \mathrm{PC} 3$ and PC4, normalize by their standard deviation, for real-time monitoring of the BSISO from May 1 to Oct 31, 2011 (a) OLR
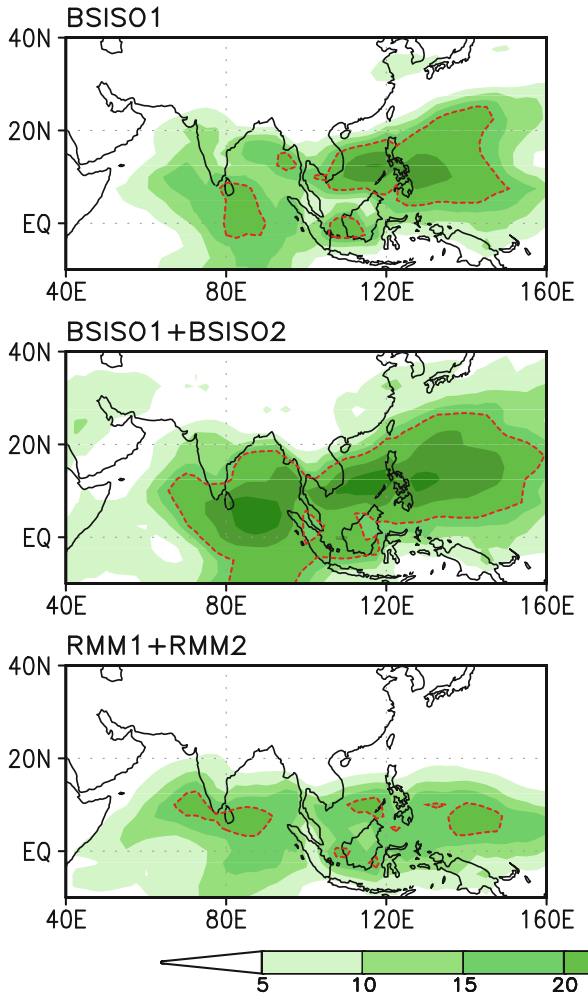

(b) 4850
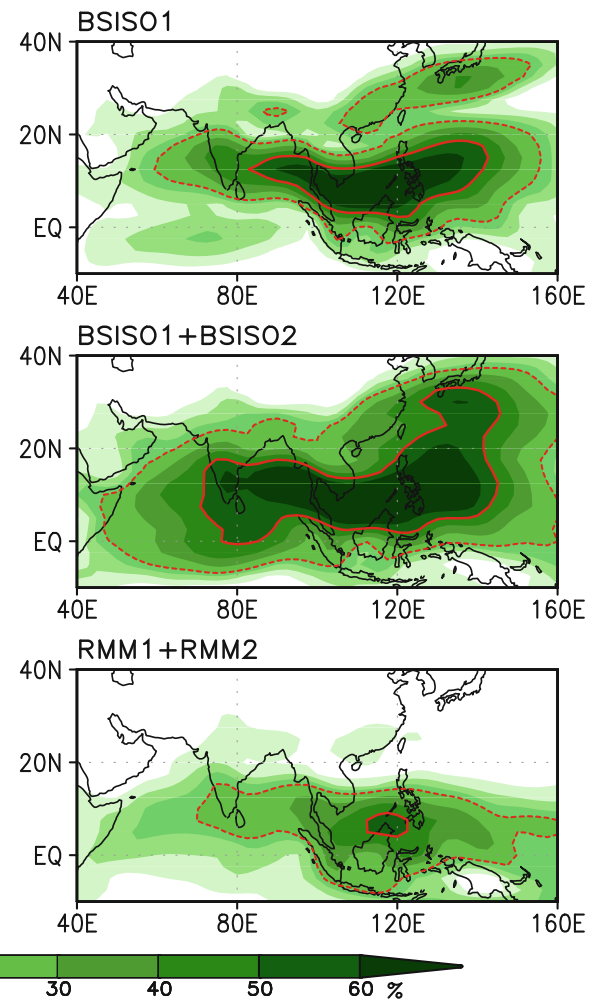

(a) BSISO 1

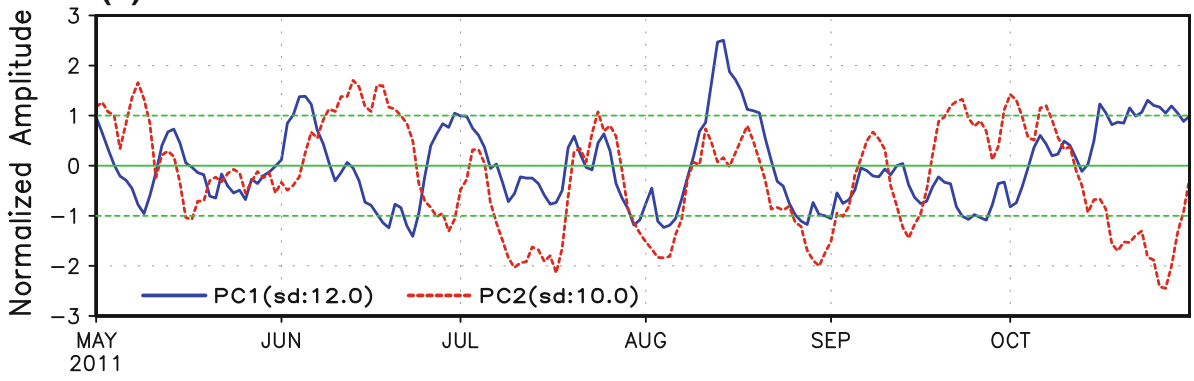

(b) $\mathrm{BSISO} 2$

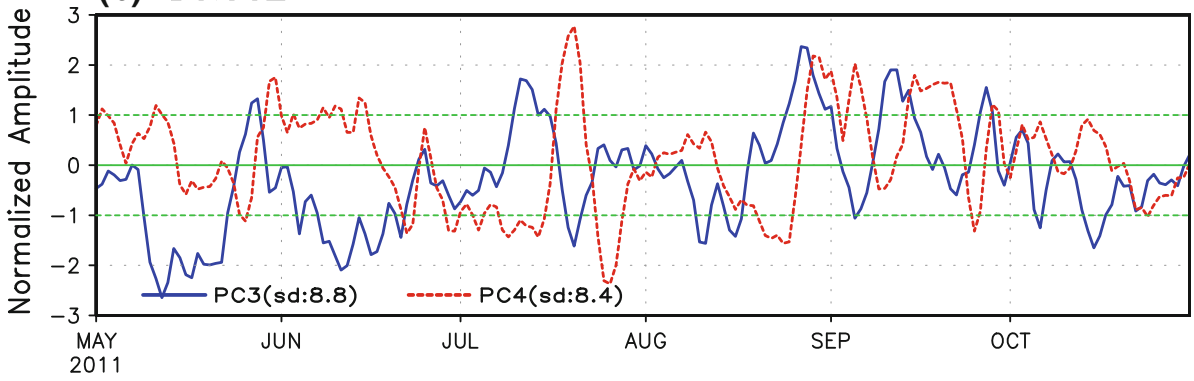

WNP-EA region. The composite life cycle of BSISO2 over the WNP-EA region also resembles the statistically significant and predominant ISO mode of summer Yangtze rainfall in response to ISO in the western North Pacific subtropical high and South China Sea shown in Fig. 5 of Mao et al. (2010). It is also noted that the BSISO2 composites reflects 10-20 day rainfall variability over the Bay of Bengal that was described by Ma et al. (2012). We further investigate the relationship between BSISO2 and summer monsoon onsets over India and the South China Sea. Monsoon onset dates at Kerala were used for the ISM from 1981 to 2007 subjectively defined by the Indian 
(a) BSISO1

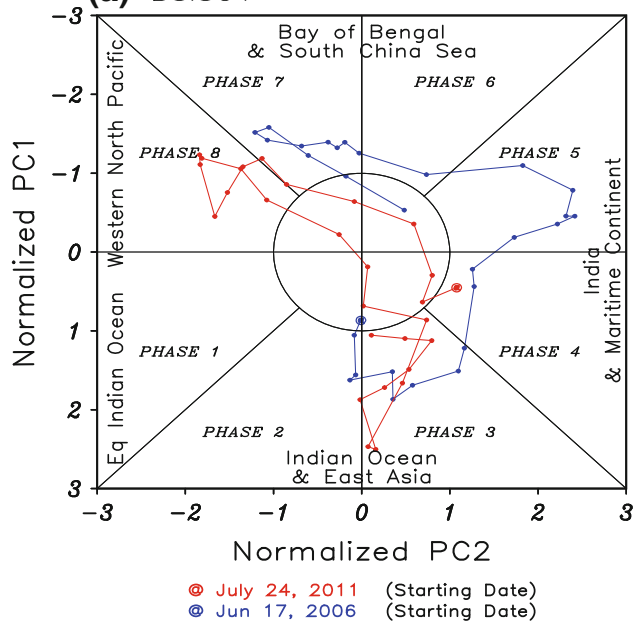

(b) $\mathrm{BSISO} 2$

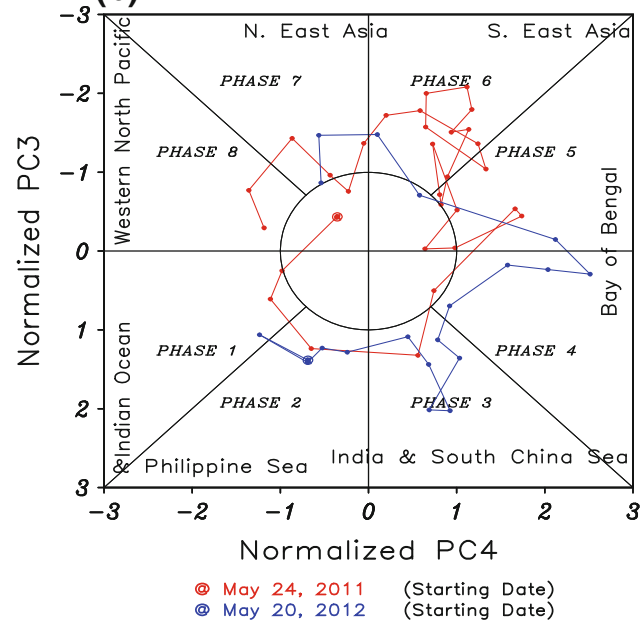

Fig. 14 a PC2 and PC1 phase space curves starting from July 24, 2011 and June 17, 2006. b PC4 and PC3 phase space curves starting from May 24, 2011 and May 20, 2012

Fig. 15 Five-day mean OLR (shading) and 850-hPa wind (vector) anomalies from 25-90 July to 29 August-2 September, 2011
Meteorological Department (Wang et al. 2009b). South China Sea monsoon onset dates used were obtained from Kajikawa and Wang (2012) from 1981 to 2008 and the onset dates were defined based on $850-\mathrm{hPa}$ zonal wind
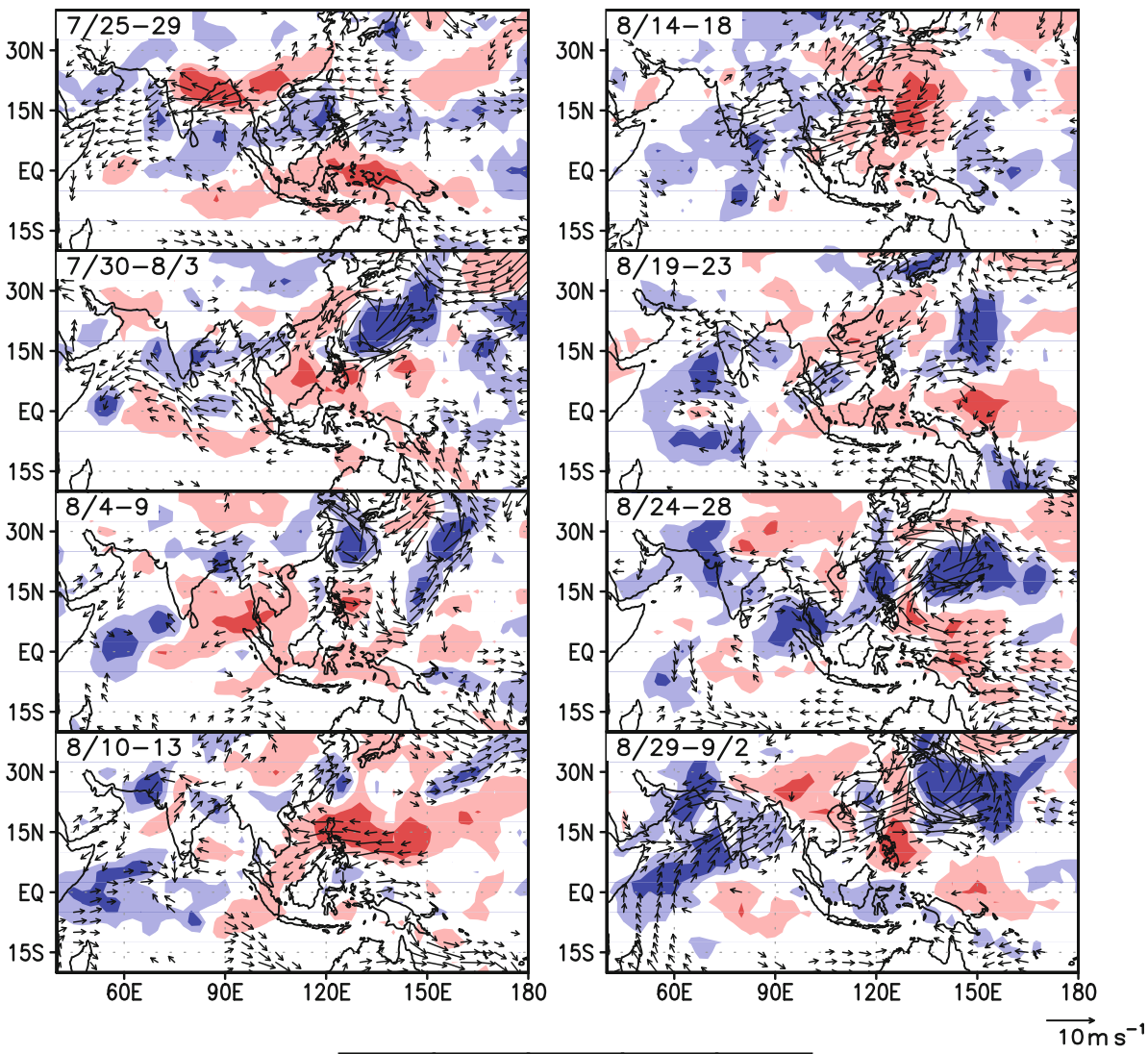

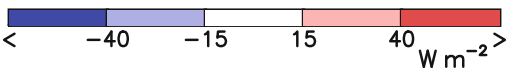

averaging over $5^{\circ}-15^{\circ} \mathrm{N}, 110^{\circ}-120^{\circ} \mathrm{E}$. Figure 11 a indicates that 18 out of 28 cases of Indian monsoon onset occur in phases 2-4 when the BSISO2-related convection is located over India and the Bay of Bengal. Figure 11b shows that 19 
out of 29 cases of the South China Sea monsoon onset occur in phases 2-4 when the BSISO2-related convection is in the Philippine Sea and the South China Sea. If one considers only the onsets that occur when BSISO2 is evident (amplitude is outside the unit circle), then $68 \%$ (70 \%) of the dates for the ISM (South China Sea) occur in phases 2-4 indicating a close relationship between BSISO2 and monsoon onset dates. The onset dates may occur in other phases because there are other factors that influence BSISO2 and stochastic processes can limit the prediction of the monsoon onset dates.

\subsection{Fractional Variance}

Figure 12 shows the fractional variance of unfiltered pentadmean OLR and U850 anomalies explained by the first two PCs (BSISO1) and the first four PCs (BSISO1 + BSISO2) together with those explained by RMM1 and RMM2. BSISO1 and BSISO2 capture a significant portion of the total variance particularly over the WNP-EA region during boreal summer while the RMM index describes the OLR variance primarily in the equatorial region and only moderately captures variability over the ISM region.

\section{Application to real-time monitoring}

The BSISO1 and BSISO2 indices proposed in this study can be applied to real-time monitoring of the BSISO over the ASM region, similar to the real-time monitoring of the eastward propagating MJO with the RMM index. Figure 13 shows time series of the projected first four PCs during the 2011 summer. PC1 and PC2 show significant amplitude from July to October, while PC3 and PC4 had prominent amplitude during May to July and from late August to early September, consistent with their climatological annual cycles in Fig. 4.

An alternative to looking at the individual PC series is the use of the phase space presentation as shown in Fig. 14, which shows some examples from different years. In summer 2011, two BSISO events are illustrated, one beginning from 24th May in BSISO2 (Fig. 14b) and the other starting from 24th July in BSISO1 (Fig. 14a). During the first event, a weak large-scale convective anomaly was initially located around the equatorial Western Indian Ocean and subtropical Western Pacific (Phase 8 of BSISO2) on 24th May, and then propagated to the Indian Ocean and Philippine Sea (Phase 2) on 27th May. Over the
Fig. 16 Same as Fig. 15 except from 10-14 June to 14-19 July, 2006

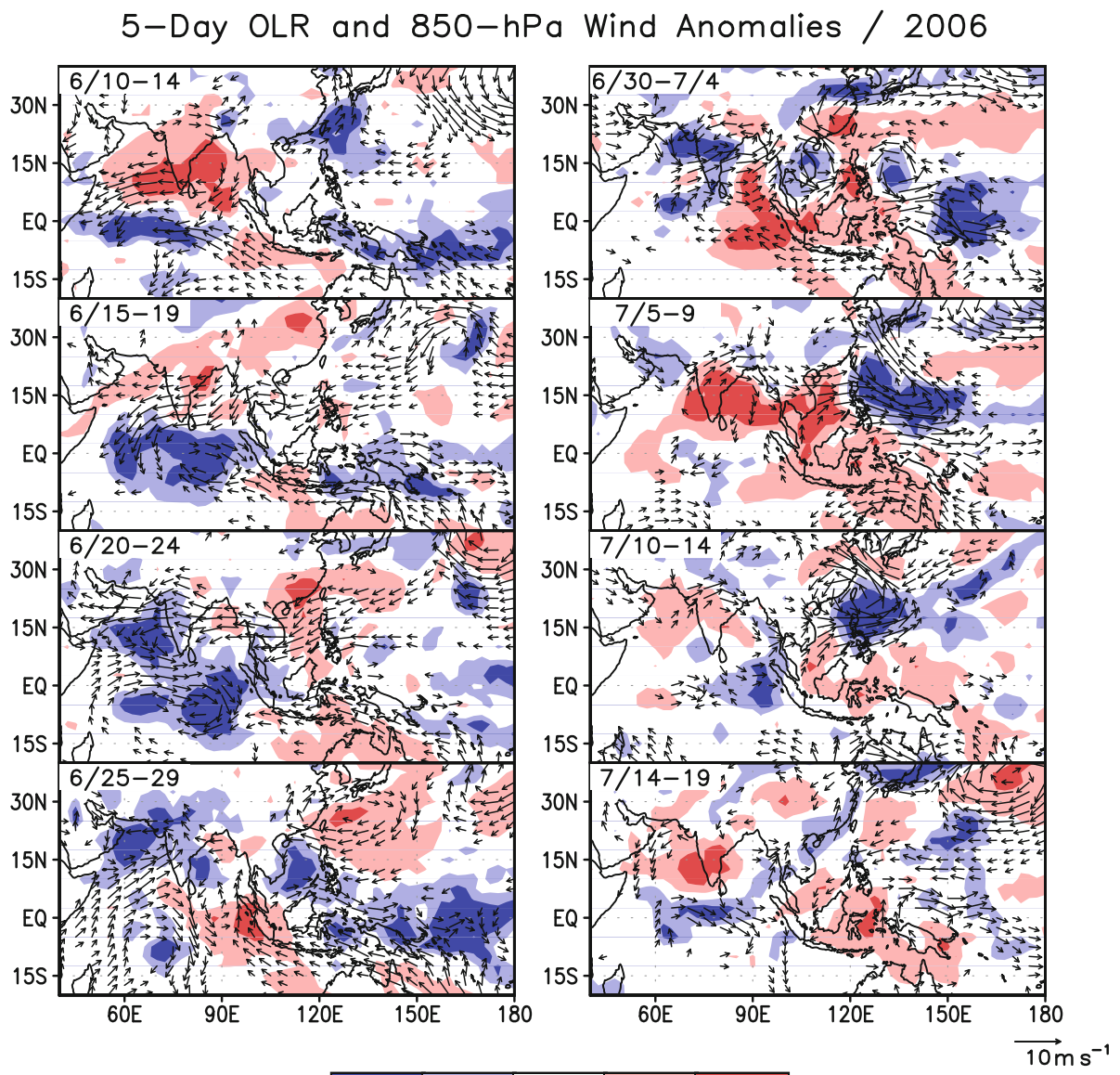


ISM region, enhanced convection propagated eastward and then northward with increased amplitude reaching the Bay of Bengal toward the end of May. Over the WNP-EA region, enhanced convection propagated northwestward reaching the South China Sea on 29th May and South Asia on 4th June. It has been recognized that East Asia had early onset in summer 2011 (Seo et al. 2012), which is well represented by the time evolution of BSISO2. The phase space of BSISO2 is also able to capture the stepwise monsoon onset during early summer 2012 shown in Fig. 14b.

While the BSISO2 event during early summer of 2011 shows approximately circular evolution, the BSISO1 event from late July to mid-August has a rather skewed evolution, particularly during Phases 1 and 2 (Fig. 14a). The skewed evolution along with the coherent relationship between the PC1 and PC2 during July and August in Fig. 13a indicate that the ISO during the period may be different from the typical BSISO1 evolution. The evolution

(a) ISMI vs BSISO index

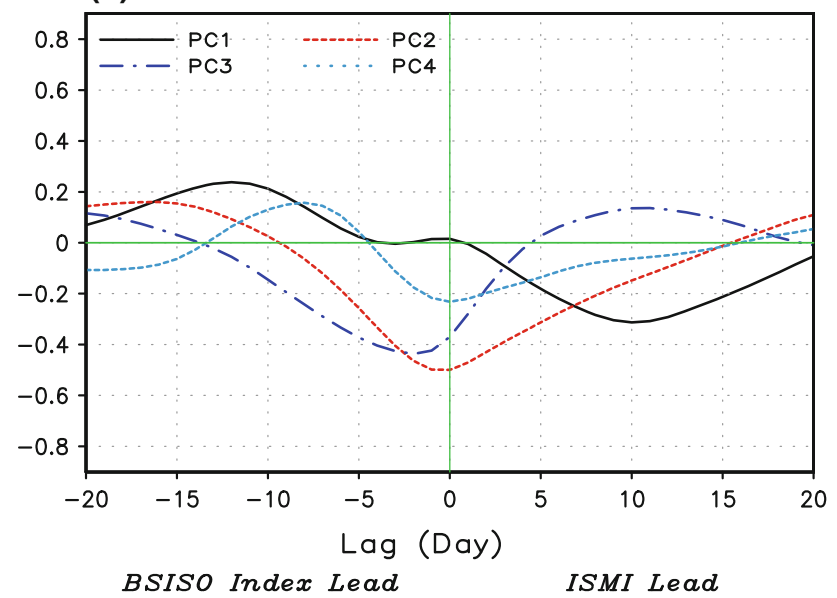

(b) WNPSMI vs BSISO Index

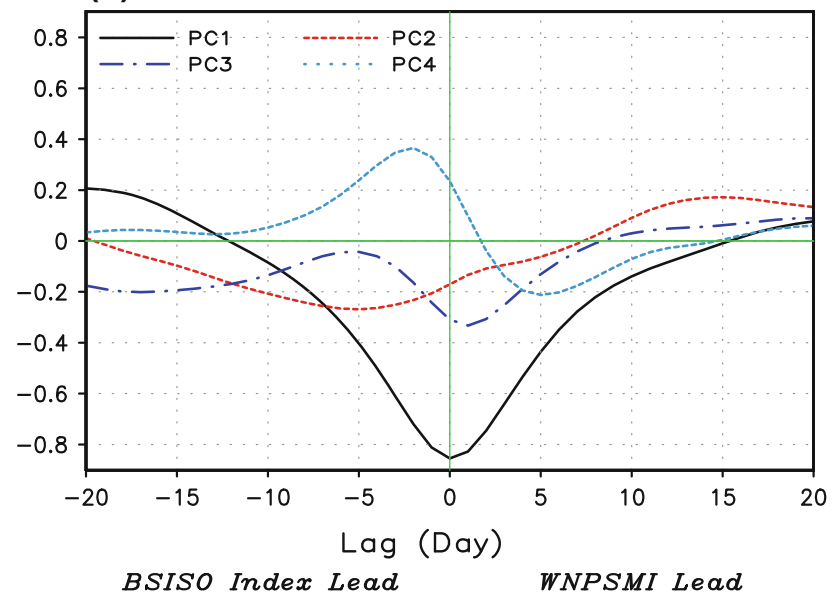

Fig. 17 Lead-lag correlation coefficients for each of PCs against a ISMI and b WNPSMI of 5-day mean OLR and 850-hPa wind anomalies from July 25 to August 29, 2011 in Fig. 15 supports that the ISO activities are different from the typical mode shown in Fig. 9. During the period, convective activities over the ISM region was relatively week and the ISO evolution looks more like a standing oscillation between Phases 7/8 and $3 / 4$, corresponding to convection shifting between the WNP and EA region. In contrast, the BSISO1 event starting from 17th June 2006 shows circular evolution from Phase 2-7 with maximum convective activity over the Indian continent and Maritime Continent. Figure 16 shows that ISO activities during the period well resembles the typical BSISO1 evolution shown in Fig. 9.

Examples shown in this section demonstrate that the BSISO1 and BSISO2 indices are capable of identifying and monitoring prominent BSISO events over the entire ASM region.

\section{Summary and Discussion}

Given the extreme importance of the BSISO, we have made an effort to define new indices to assist in real-time monitoring and forecast applications of the BSISO. The BSISO indices proposed in this study were designed to better represent fractional variance and the observed northward/northwestward propagating ISO over the ASM region than the RMM index. Albeit its excellence in measuring the equatorial eastward propagating MJO, the RMM index is limited in its ability to capture ISO activity during boreal summer when it is furthest from the equator.

After considerable sensitivity tests, our chosen method to define the new BSISO indices uses the MV-EOF analysis of daily mean OLR and U850 anomalies over the ASM region $\left(10^{\circ} \mathrm{S}-40^{\circ} \mathrm{N}, 40^{\circ}-160^{\circ} \mathrm{E}\right)$ from May to October for the 30 years 1981-2010. The OLR and U850 anomalies are obtained from removing the slow annual cycle as well as the effect of interannual variation through subtracting the running mean of the last 120 days. We do not apply any other time filtering. We identify the first four MV-EOF modes as important for representing the BSISO over the ASM region that account for $19.4 \%$ of total daily variance of the combined OLR and U850 anomalies. Based on our analysis, two BSISO indices are proposed: BSISO1 comprises the first two MV-EOF modes, and BSISO2 consists of the 3rd and 4th modes.

BSISO1 represents the canonical northward and northeastward propagating ISO over the ASM region during the entire warm season from May to October with quasioscillating periods of 30-60 days in conjunction with the eastward propagating MJO (e.g., Annamalai and Sperber 2005; Wang et al. 2005; Kikuchi et al. 2012). EOF1 and EOF2 can be treated together as a pair to form what we call 
BSISO1 because of the following three reasons. First, EOF1 and EOF2 exhibit similarity in their spatial structure characterized by a northwest to southeast slope. Second, the mean seasonal cycle of variance of $\mathrm{PC} 1$ is similar to that of PC2 with strong variance throughout the May to October period. Third, PC1 and PC2 have significant coherence in the 30- to 60-day range with a $90^{\circ}$ phase difference indicating that $\mathrm{PC} 1$ leads $\mathrm{PC} 2$ by a quarter cycle. Analysis of lag correlation coefficients between the PCs further reveals that PC1 tends to lead PC2 by about 13 days with a maximum correlation of 0.34 for non-filtered data, and 0.45 for 30 - to 60 -day filtered data.

BSISO 2, on the other hand, mainly captures the northward and northwestward propagation components of the BSISO, particularly during pre-monsoon and monsoon onset period. Different to the first two modes, the OLR and U850 patterns in EOF3 and EOF4 tend to be more in phase over the ISM and WNP region with a southwest-northeast tilted horizontal structure. The structure of EOF4 resembles the 'climatological ISO' of Kang et al. (1999) and the fast annual cycle pattern of the pre-monsoon and onset period of LinHo and Wang (2002). Consistently, PC3 and PC4 have maximum variance from late May to early July and the bulk of their variance is concentrated at around 30 days (PC3) and in the 10- to 20-day range (PC4). With high coherence in the 10- to 20-day range and at $\sim 30$ days, PC 3 tends to lead PC4 by about 3-4 days for variability in the 10 - to 20-day period range, and at a lag of 7-8 days for variability in the 20- to 50-day range. These relatively high coherence values, their similar horizontal tilts, and similar climatological seasonal cycles lead us to conclude that third and fourth MV-EOF modes should be treated together as a pair, which we call BSISO2. BSISO2 has a close relationship with the onset of the ASM. Considering only monsoon onsets that occur when the BSISO2 amplitude is outside the unit circle, $68 \%$ (70\%) of the onset dates for the Indian (South China Sea) monsoon occur in Phases 2-4.

The composite life cycles of BSISO1 and BSISO2 well demonstrate the circulation patterns associated with each index. The BSISO1 circulation cells are more Rossby wave like, whereas the circulation associated with BSISO2 is more elongated and front-like. We further demonstrate that the BSISO indices proposed in this study can be applied to realtime monitoring of the BSISO similar to the real-time monitoring of the eastward propagating MJO with the RMM index.

Previously-defined indices of the boreal summer monsoon circulation are the Indian Summer Monsoon Index (ISMI) and the Western North Pacific Summer Monsoon Index (WNPSMI; Wang and Fan 1999; Wang et al. 2001, 2004). Figure 17 provides the lag correlation between each $\mathrm{PC}$ and these other indices. It is shown that PC1 reflects most of the WNPSMI variability with a maximum simultaneous correlation of -0.85 and PC2 significantly correlates with the ISMI with a maximum correlation of -0.57 when PC2 leads ISMI by 1 day. Noting that the PCs are orthogonal, the total variance explained by the PCs can be computed by summing their squared values. Thus for the ISMI the PCs account for $45 \%$ of the variance of the ISMI at zero lag and for the WNPSMI the PCs account for $88 \%$ of the variance at zero lag.

Although the BSISO indices are derived in the ASM domain, it is also indicative of the ISO in the North American monsoon region. This is because when intraseasonal convective anomalies occur in the equatorial western Pacific, they move not only northwestward toward the Philippine Sea but also eastward along the Intertropical Convergence Zone toward the North American monsoon region. As shown by Wang et al. (2005) and Moon et al. (2012), the ISO over the Mexican monsoon tends to be out of phase with the ISO over the southern Bay of Bengal. In terms of BSISO1, the peak in intraseasonal convective activity over the Mexican monsoon area occurs in Phase 1. This makes it also somewhat possible to monitor the North American monsoon by using BSISO1.

Acknowledgments We thank the organization and members of the WWRP/THORPEX/WCRP YOTC MJO Task Force for their insights. We also thank two anonymous reviewers for their valuable comments that helped to improve our manuscript. JYL, BW, XF, and DW acknowledge support from the NOAA/MAPP project Award number NA10OAR4310247, AMDT1. BW and XF acknowledge support from Climate Dynamics Program of the National Science Foundation under award No AGS-1005599. This study has been also supported by APEC Climate Center and International Pacific Research Center, which is in part supported by JAMSTEC, NOAA (NA09OAR4320075) and NASA (NNX07AG53G). DW's contribution was carried out at the Jet Propulsion Laboratory, California Institute of Technology, under a contract with the National Aeronautics and Space Administration. ISK were supported by the National Research Foundation of Korea (NRF) Grand Funded by the Korean Government (MEST) (NRF-2009-C1AAA001-20090093042). This is the SEOST publication number 8744 and IPRC publication number 912 .

Open Access This article is distributed under the terms of the Creative Commons Attribution License which permits any use, distribution, and reproduction in any medium, provided the original author(s) and the source are credited.

\section{References}

Annamalai H, Slingo JM (2001) Active/break cycles: diagnosis of the intraseasonal variability of the Asian summer monsoon. Clim Dyn 18:85-102

Annamalai H, Sperber KR (2005) Regional heat sources and the active and break phases of boreal summer intraseasonal (30-50 day) variability. J Atmos Sci 62:2726-2748

Chen TC, Chen JM (1993) The 10-20 day mode of the 1979 Indian monsoon: its relation with the time variation of monsoon rainfall. Mon Weather Rev 121:2465-2482 
CLIVAR Madden-Julian Oscillation Working Group (2009) MJO simulation diagnostics. J Clim 22:3006-3030

Ding Q, Wang B (2005) Circumglobal teleconnection in the Northern Hemisphere summer. J Clim 18:3483-3505

Ding Q, Wang B (2009) Predicting extreme phases of the Indian summer monsoon. J Clim 22:346-363

Goswami BN (2005) South Asian monsoon. In: Lau KM, Waliser DE (eds) Intraseasonal variability of the ocean and atmosphere. Springer, Heidelberg, pp 19-61

Gottschalck J, Wheeler M, Weickmann K, Vitart F, Savage N et al (2010) A framework for assessing operational Madden-Julian oscillation forecasts: a CLIVAR MJO working group project. Bull Am Meteorol Soc 91:1247-1258

Hoyos CD, Webster PJ (2007) The role of intraseasonal variability in the Nature of Asian monsoon precipitation. J Clim 20:4402-4424

Hsu HH, Weng CH (2001) Northwestward propagation of the intraseasonal oscillation during the boreal summer: mechanism and structure. J Clim 14:3834-3850

Jiang X, Li T, Wang B (2004) Structures and mechanisms of the northward-propagating boreal summer intraseasonal oscillation. J Clim 17:1022-1039

Kajikawa Y, Wang B (2012) Interdecadal change of the South China Sea summer monsoon onset. J Clim 25:3207-3218

Kajikawa Y, Yasunari T (2005) Interannual variability of the 10-25- and 30-60-day variation over the South China Sea during boreal summer. Geophys Res Lett 32:L04710. doi:10.1029/2004 GL021836

Kanamitsu M et al (2002) NCEP dynamical seasonal forecast system 2000. Bull Am Meteorol Soc 83:1019-1037

Kang IS, Ho CH, Lim YK, Lau KM (1999) Principal modes of climatological seasonal and intraseasonal variations of the Asian summer monsoon. Mon Weather Rev 127:322-340

Kemball-Cook S, Wang B (2001) Equatorial waves and air-sea interaction in the boreal summer intraseasonal oscillation. J Clim 14:2923-2942

Kikuchi K, Wang B (2010) Formation of tropical cyclones in the northern Indian Ocean associated with two types of tropical intraseasonal oscillation modes. J Meteorol Soc Jpn 88:475-496

Kikuchi K, Wang B, Kajikawa Y (2012) Bimodal representation of the tropical Intraseasonal oscillation. Clim Dyn 38:1989-2000

Kim D et al (2009) Application of MJO simulation diagnostics to climate models. J Clim 22:6413-6436

Krishnamurthy V, Shukla J (2007) Intraseasonal and seasonally persisting patterns of Indian monsoon rainfall. J Clim 20:3-20

Krishnamurthy V, Shukla J (2008) Seasonal persistence and propagation of intraseasonal patterns over the Indian monsoon region. Clim Dyn 30:353-369

Krishnamurti TN, Subramanian D (1982) The 30-50 day mode at 850 mb during MONEX. J Atmos Sci 39:2088-2095

Lau WKM, Chan PH (1986) Aspects of the 40-50 day oscillation during the northern summer as inferred from outgoing long wave radiation. Mon Weather Rev 114:1354-1367

Lau WKM, Waliser DE (eds) (2005) Intraseasonal variability of the atmosphere-ocean climate system. Springer, Heidelberg

Lawrence DM, Webster PJ (2002) The boreal summer intraseasonal oscillation: relationship between northward and eastward movement of convection. J Atmos Sci 59:1593-1606

Lee JY, Wang B, Kang IS, Shukla J et al (2010) How are seasonal prediction skills related to models' performance on mean state and annual cycle? Clim Dyn 35:267-283

Lee JY, Wang B, Ding Q, Ha KJ, Ahn JB, Kumar A, Stern B, Alves O (2011) How predictable is the northern hemisphere summer upper-tropospheric circulation? Clim Dyn 37:1189-1203

Leroy A, Wheeler MC (2008) Statistical prediction of weekly tropical cyclone activity in the Southern Hemisphere. Mon Weather Rev $136: 3637-3654$
Liebmann B, Smith CA (1996) Description of a complete (interpolated) outgoing longwave radiation dataset. Bull Am Meteorol Soc 77:1275-1277

LinHo, Wang B (2002) The time-space structure of the Asian-Pacific summer monsoon: a fast annual cycle view. J Clim 15:2001-2019

Livezey RE, Chen WY (1983) Statistical field significance and its determination by Monte Carlo techniques. Mon Weather Rev 111:46-59

Ma S, Rodo X, Song Y, Cash BA (2012) Dynamical linkage of tropical and subtropical weather systems to the intraseasonal oscillations of the Indian summer monsoon rainfall. Part I: observations. Clim Dyn 39:557-572

Madden RA (1986) Seasonal-variations of the 40-50 day oscillation in the tropics. J Atmos Sci 43:3138-3158

Madden RA, Julian PR (1972) Description of global-scale circulation cells in tropics with a 40-50 day period. J Atmos Sci 29:1109-1123

Madden RA, Julian PR (1994) Observations of the 40-50-day tropical oscillation-a review. Mon Weather Rev 122:814-837

Mao J, Sun Z, Wu G (2010) 20-50-day oscillation of summer Yangtze rainfall in response to intraseasonal variations in the subtropical high over the western North Pacific and South China Sea. Clim Dyn 34:747-761

Moon JY, Wang B, Ha KJ, Lee JY (2012) Teleconnections associated with Northern Hemisphere summer monsoon intraseasonal oscillation. Clim Dyn. doi:10.1007/s00382-012-1394-0

Murakami M (1984) Analysis of deep convective activity over the western Pacific and southeast Asia. Part II: seasonal and intraseasonal variations during northern summer. J Meteorol Soc Jpn 62:88-108

North GR, Bell TL, Cahalan RF, Moeng FJ (1982) Sampling errors in the estimation of empirical orthogonal functions. Mon Weather Rev 110:699-706

Rashid HA, Hendon HH, Wheeler MC, Alves O (2011) Prediction of the Madden-Julian oscillation with the POAMA dynamical prediction system. Clim Dyn 36:649-661

Salby ML, Hendon HH (1994) Intraseasonal behavior of clouds, temperature, and motion in the tropics. J Atmos Sci 51:2207-2224

Seo KH, Son JH, Lee SE, Tomita T, Park HS (2012) Mechanisms of an extraordinary East Asian summer monsoon event in July 2011. Geophys Res Lett 39:L05704

Waliser DE, Murtugudde R, Lucas LE (2004) Indo-Pacific Ocean response to atmospheric intraseasonal variability: 2. Boreal summer and the intraseasonal oscillation. J Geophys Res 109:C03030. doi:10.1029/2003JC002002

Wang B, Ding Q (2008) The global monsoon: major modes of annual variation in tropical precipitation and circulation. Dyn Atmos Oceans 44:165-183

Wang B, Fan Z (1999) Choice of South Asian summer monsoon indices. Bull Am Meteorol Soc 80:629-638

Wang B, Rui H (1990) Synoptic climatology of transient tropical intraseasonal convection anomalies: 1975-1985. Meteorol Atmos Phys 44:43-61

Wang B, Xie X (1997) A model for the boreal summer intraseasonal oscillation. J Atmos Sci 54:72-86

Wang B, Wu RG, Lau KM (2001) Interannual variability of the Asian summer monsoon: contrasts between the Indian and the western North Pacific-east Asian monsoon. J Clim 14:4073-4090

Wang B, Kang IS, Lee JY (2004) Ensemble simulations of AsianAustralian monsoon variability by 11 AGCMs. J Clim 17:819-833

Wang B, Webster PJ, Teng H (2005) Antecedents and self-induction of the active-break Indian summer monsoon. Geophys Res Lett 32:L04704. doi:10.1029/2004GL020996 
Wang B, Lee JY, Shukla J, Kang IS et al (2009a) Advance and prospectus of seasonal prediction: assessment of APCC/CliPAS 14-model ensemble retrospective seasonal prediction (1980-2004). Clim Dyn 33:93-117

Wang B, Ding Q, Joseph PV (2009b) Objective definition of the Indian summer monsoon onset. J Clim 22:3303-3316

Wang H, Wang B, Huang F, Ding Q, Lee JY (2012) Interdecadal change of the boreal summer circumglobal teleconnection (1958-2010). Geophys Res Lett 39:L12704. doi:10.1029/2012G L052371

Webster PJ et al (1998) Monsoon: processes, predictability and the prospects for prediction. J Geophys Res 103:14451-14510

Wheeler MC, Hendon HH (2004) An all-season real-time multivariate MJO index: development of an index for monitoring and prediction. Mon Weather Rev 132:1917-1932

Wheeler MC, Hendon HH, Cleland S, Meinke H, Donald A (2009) Impacts of the Madden-Julian oscillation on Australian rainfall and circulation. J Clim 22:1482-1498
Yasunari T (1979) Cloudiness fluctuations associated with the northern hemisphere summer monsoon. J Meteorol Soc Jpn $57: 227-242$

Yasunari T (1980) A quasi-stationary appearance of 30 to 40 day period in the cloudiness fluctuation during the summer monsoon over India. J Meteorol Soc Jpn 58:225-229

Yun KS, Ha KJ, Ren B, Chan JCL, Jhun JG (2009) The 30-60 day oscillation in the East Asian summer monsoon and its timedependent association with the ENSO. Tellus A 61A:565-578

Yun KS, Seo KH, Ha KJ (2010) Interdecadal change in the relationship between ENSO and the intraseasonal oscillation in East Asia. J Clim 23:3599-3612

Zhang CD (2005) Madden-Julian oscillation. Rev Geophys 43:RG2003. doi:10.1029/2004RG000158

Zhang CD, Dong M (2004) Seasonality in the Madden-Julian oscillation. J Clim 17:3169-3180 